\title{
Non-Coding RNAs in Glioma
}

\author{
Ryte Rynkeviciene ${ }^{1}$, Julija Simiene ${ }^{1,2}$, Egle Strainiene ${ }^{1,3}$, Vaidotas Stankevicius ${ }^{1,4}$, \\ Jurgita Usinskiene ${ }^{1}$, Edita Miseikyte Kaubriene ${ }^{1,5}$, Ingrida Meskinyte ${ }^{6,7}$, Jonas Cicenas ${ }^{6,7,8}$ (D) \\ and Kestutis Suziedelis $1,2, *$ (D)
}

1 Nacional Cancer Institute, Santariskiu str. 1, LT-08660 Vilnius, Lithuania; ryte.rynkeviciene@nvi.lt (R.R.); julija.fadejeva@nvi.lt (J.S.); egle.strainiene@nvi.lt (E.S.); vaidotas.stankevicius@nvi.lt (V.S.); jurgita.usinskiene@nvi.lt (J.U.); edita.kaubriene@nvi.lt (E.M.K.)

2 Institute of Biosciences, Life Sciences Center, Vilnius University, Sauletekio ave. 7, LT-08412 Vilnius, Lithuania

3 Department of Chemistry and Bioengineering, Vilnius Gediminas Technical University, Sauletekio ave. 11, LT-10122 Vilnius, Lithuania

4 Institute of Biotechnology, Vilnius University, LT-10257 Vilnius, Lithuania

5 Faculty of Medicine, Vilnius University, M.K. C`iurlionio 21, LT-03101 Vilnius, Lithuania

6 Proteomics Center, Institute of Biochemistry, Vilnius University Life Sciences Center, Sauletekio al. 7, LT-10257 Vilnius, Lithuania; ingrida.meskinyte@gmail.com (I.M.); j.cicenas@mapkinases.eu (J.C.)

7 MAP Kinase Resource, Bioinformatics, Melchiorstrasse 9, 3027 Bern, Switzerland

8 Energy and Biotechnology Engineering Institute, Aleksandro Stulginskio University, Studentu g. 11, LT-53361 Akademija, Lithuania

* Correspondence: kestutis.suziedelis@gf.vu.lt or kestutis.suziedelis@nvi.lt; Tel.: +370-5-219-0904

Received: 9 November 2018; Accepted: 19 December 2018; Published: 22 December 2018

\begin{abstract}
Glioma is the most aggressive brain tumor of the central nervous system. The ability of glioma cells to migrate, rapidly diffuse and invade normal adjacent tissue, their sustained proliferation, and heterogeneity contribute to an overall survival of approximately 15 months for most patients with high grade glioma. Numerous studies indicate that non-coding RNA species have critical functions across biological processes that regulate glioma initiation and progression. Recently, new data emerged, which shows that the cross-regulation between long non-coding RNAs and small non-coding RNAs contribute to phenotypic diversity of glioblastoma subclasses. In this paper, we review data of long non-coding RNA expression, which was evaluated in human glioma tissue samples during a five-year period. Thus, this review summarizes the following: (I) the role of non-coding RNAs in glioblastoma pathogenesis, (II) the potential application of non-coding RNA species in glioma-grading, (III) crosstalk between lncRNAs and miRNAs (IV) future perspectives of non-coding RNAs as biomarkers for glioma.
\end{abstract}

Keywords: non-coding RNA; glioma; miRNA; lncRNA

\section{Introduction}

Glioma is one of the most aggressive and common primary tumors ( $\sim 30 \%)$ of the central nervous system (CNS), which includes astrocytoma, oligodendroglioma, ependymoma, medulloblastoma and glioblastoma. Despite the progress in surgical resection, radiotherapy and chemotherapy technologies, the prognosis for glioma patients remains poor [1]. The median survival for patients with a high-grade glioma is only 15 months [2]. A better understanding of tumor characteristics and biology is necessary for better tumor classification and patient stratification. Over the past decades, the bulk of glioma and other cancer research was pointed towards the identification of altered gene expression, mutations and epigenetic modifications, which could serve as a molecular biomarkers [3]. In 2016 a new and 
improved classification of gliomas was approved as a direct result of this research [4]. This new classification takes molecular biomarkers into account thus allowing for more precision. Diffuse astrocytic and oligodendroglial tumors (WHO II and III) are now separated according to IDH mutation and $1 \mathrm{p} / 19 \mathrm{q}$-codeletion status. Also grade IV gliomas are now divided into IDH wild type, IDH-mutant, glioblastoma not otherwise specified (NOS) and diffuse midline glioma, H3 K27M-mutant. Of all adult brain tumors, about $32 \%$ are malignant. $46.88 \%$ of malignant tumors are glioblastomas. Another large group of brain tumors are diffuse astrocytomas $-17.19 \%$. Oligodendroglioma and ependymal tumors comprise $4.69 \%$ and $6.25 \%$ of adult brain tumours, respectfully. The remaining $25 \%$ are other malignant tumors [5].

Diffuse low grade gliomas (WHO II) such as diffuse astrocytoma and oligodendroglioma are classified into three subgroups: (a) low-risk low-grade, IDH-mutant $+/-1 \mathrm{p} / 19 \mathrm{q}$ co-deleted tumors. Patients are usually less than 40 years old. More than 14 years of survival can be achieved after maximal safe resection combined with radiotherapy; (b) high-risk low grade large $(>5 \mathrm{~cm})$ tumors, patient age over 40, IDH-wild type, often treated as glioblastoma. Survival prognosis is about 5 years; (c) IDH-mutant high-risk low grade gliomas, progression-free survival is 3-5 years. Recent phase 3 trial RTOG 9802 showed that initial radiation followed by procarbazine, lomustine and vincristine (PVC) prologs the survival from 4.0 to 10.4 years [6].

Diffuse high-grade gliomas (WHO III) include anaplastic astrocytoma IDH-mutant, IDH-wild type and NOS, anaplastic oligodendroglioma IDH-mutant/1p/19q co-deleted and NOS. CATNON clinical 3 phase trial revealed that anaplastic astrocytoma with intact $1 \mathrm{p} / 19 \mathrm{q}$ status with additional 12 cycles of temozolomide to radiotherapy prolong progression-free survival from 1.5 to 3.6 years [7]. The usage of PVC instead of TMZ is investigated in CODEL trial [8].

Glioblastoma (WHO IV) is the most lethal and most common brain cancer, with a very short survival. Only about $5 \%$ of patients survive beyond 5 years. The standard treatment for good performance patients consists of radiotherapy to 60 Gy over 3 weeks with daily TMZ, followed by at least six cycles of adjuvant TMZ [9]. Recent trials reported increased survival with the addition of electric field therapy. It was shown that electric field therapy can prolong survival by nearly 5 months [10].

However, there is still a lot of research needed to fully understand the regulation of cell processes in order to make use of new biomarkers and new technologies as tools to improve the treatment of glioma. Non-coding RNAs, which are involved in global regulation of cellular processes, can be used as potential biomarkers in cancer [11].

Whole genome sequencing revealed that more than $90 \%$ of the human genome is transcribed and only $\sim 3 \%$ of the genome contains protein-coding genes [12]. The rest of the genome encodes mainly non-coding RNA. These RNAs are split into two classes: housekeeping and regulatory RNAs. tRNA, rRNA, snRNA and snoRNA belong to these housekeeping RNA classes responsible for maintaining a constant protein expression level in the cells. The rest of non-coding RNAs regulate gene expression and are divided into two subclasses according to their length. RNAs that are less than $200 \mathrm{nt}$ represent the subclass of small non-coding RNAs (sncRNA). In addition, sncRNAs include a group of related RNAs such as miRNA, piRNA and siRNA. If non-coding RNAs are longer than $200 \mathrm{nt}$, they are classified as long non-coding RNAs (lncRNAs) [13].

LncRNAs are mainly polyadenylated $200 \mathrm{nt}-100 \mathrm{~kb}$ long transcripts, usually transcribed by RNA polymerase II and controlled by multiple type of transcriptional factors. LncRNAs is the largest $(>80 \%)$ and a very heterogeneous group of ncRNAs, but is less conserved than miRNA [14]. and According to their position in the genome, all lncRNAs can be divided into the following subclasses: sense, antisense, bidirectional, intronic and intergenic [15]. Transcription of lncRNAs may affect the down-stream gene expression either positively or negatively by directly interfering with promoters or by modifying the structure of chromatin. LncRNAs also bind specific proteins such as PcG, Enhancer of zeste homolog 2 (Ezh2), a histone methyltransferase and Polycomb-repressive complex 2 (PRC2) by modulating protein activity, altering its localization or changing its structural or organizational 
role [16]. Thus, IncRNA-protein interactions may modulate the activity of other protein-binding partners. Recent genome studies suggest that long non-coding RNAs serve asprecursors for small RNAs [17]. Several reports prove that lncRNAs cause mRNRs to be processed into small RNAs [18]. Recent studies indicate that interactions between miRNAs and lncRNAs are able to regulate each other's expression, thus forming a complex regulatory network which plays an important role in the cell pathophysiological processes. A cross-regulation between lncRNAs and miRNAs includes processes such as miRNA triggered IncRNA decay, IncRNA affected miRNA levels and function regulation, IncRNA competition with miRNA for interaction with mRNAs and miRNA production from lncRNAs $[19,20]$. The aberrant expression and cross-regulation of miRNAs and lncRNAs can be used as potential diagnostic and therapeutic tools in different malignancies, including gliomas [21-29]. Indeed, this confirms that miRNAs, IncRNAs and other non-coding RNAs regulate a number of target genes and play an important role in glioma carcinogenesis, thus serving as predictive and prognostic biomarkers of glioma.

LncRNAs are involved in biological processes such as cell death, growth, differentiation, epigenetic regulation, genomic imprinting, alternative splicing, and regulation of gene expression at the posttranscriptional level, chromatin modification, inflammatory pathologies and subcellular transport. Invalid lncRNAs expression can be associated with cancer development, progression and metastasis formation and can be used as a therapeutic target in glioma [30,31].

Here we provide an overview of the latest studies related to lncRNAs, miRNAs, which directly target reviewed lncRNAs and other small noncoding RNAs that exhibit altered expression in glioma tissue, with a focus on their biological and therapeutic roles in brain tumors and discuss future perspectives.

\section{Expression of Non-Coding RNAs in Cell Proliferation, Migration, Invasion and Apoptosis}

\subsection{Up-Regulated lncRNAs in Biological Glioma Processes}

Cell proliferation, invasion and migration are the major characteristics of cancer cells. The ability of cancer cells to migrate and invade into the normal tissue plays a critical role in patient survival [32]. Specialized cancer cell interactions with the extracellular matrix (ECM) and adjacent cells, accompanied by various biochemical processes support active cell movement [33]. These cells release a number of growth factors such as TGF- $\beta$ (Transforming Growth Factor-beta), VEGF (Vascular Endothelial Growth Factor), PDGF (Platelet-Derived Growth Factor), FGF-2 (Fibroblast Growth Factor), alter the levels of transcription factors (Twist, Snail, ZEB) required for the initiation of the epithelial mesenchymal transition (EMT) and also release numerous proteases that promote cancer cell invasion into normal brain tissue [34]. Moreover, glioblastomas display a deregulated apoptotic pathway with high levels of anti-apoptotic family proteins Bcl-2 (B-cell lymphoma 2) and PI3K (Phosphatidylinositol-4,5-bisphosphate 3-kinase) [35]. The cell cycle control mechanisms regulated by p53 and RB (Retinoblastoma) proteins are inactive and allow unregulated cell cycle progression and tumor growth [36]. Malignant cell growth is characterized by loss of cellular identity, increased proliferation abilities and deregulation of cell death. Study results indicate that non-coding RNAs are important in this cancer-relevant cellular phenotype regulation [37].

The growing list of long-non-coding RNAs, the expression of which is up-regulated in glioma, supports their importance in proliferation and malignancy processes (Figure 1 and Table 1). 
Table 1. Long non-coding RNAs altered in glioma.

\begin{tabular}{|c|c|c|c|c|c|}
\hline lncRNA & Target miRNA & Genes and/or Pathways & Samples & Biological Processes & References \\
\hline \multirow{3}{*}{$\mathrm{AB} 073614 \uparrow$} & - & E-cadherin, Vimentin & 80 glioma & Proliferation, invasion, migration & [38] \\
\hline & - & $\mathrm{PI} 3 \mathrm{~K} / \mathrm{AKT}$ & GG-13, HGG-15 & Proliferation, invasion, migration, apoptosis & [39] \\
\hline & - & - & 65 glioma & $\begin{array}{l}\text { Poor survival } \\
\end{array}$ & [40] \\
\hline ADAMTS9-AS2 $\downarrow$ & - & ADAMTS9, DNMT1 & LGG-46, HGG-24 & $\begin{array}{l}\text { Proliferation, migration, invasion, correlates } \\
\text { with survival }\end{array}$ & [41] \\
\hline $\mathrm{ATB} \uparrow$ & miR-200a & TGF- $\beta 2$ & 79 glioma & Proliferation, migration, invasion & [42] \\
\hline \multirow{4}{*}{ CASC $2 \downarrow$} & miR-21 & - & LGG-12, HGG-12 & Proliferation, migration, invasion, apoptosis & [43] \\
\hline & miR-181a & PTEN pathway & LGG-30, HGG-27 & Proliferation, chemoresistance to TMZ & [44] \\
\hline & - & $\beta$-catenin, cyclin D1 and c-Myc & LGG-26, HGG-21 & Proliferation & [45] \\
\hline & miR-193a-5p & mTOR & LGG-15, HGG-17 & TMZ sescitivity & [46] \\
\hline \multirow{2}{*}{ CCAT1 $\uparrow$} & miR-181b & FGFR3, PDGFRA & LGG 45, HGG 41 & Proliferation & [47] \\
\hline & miR-410 & - & 28 glioma & Proliferation & [48] \\
\hline CCAT $2 \uparrow$ & - & Wnt/ $\beta$-catenin signal pathway & LGG-58, HGG-76 & Proliferation, cell cycle progression, migration & [49] \\
\hline $\mathrm{CCDC} 26 \uparrow$ & miR-203 & - & 40 glioma & Proliferation, migration, & [50] \\
\hline CCND2-AS1 $\uparrow$ & - & Wnt/ $\beta$-catenin signaling & 54 glioma & Proliferation & [51] \\
\hline \multirow{4}{*}{ CRNDE $\uparrow$} & - & - & LGG-46, HGG-118 & Proliferation & [52] \\
\hline & miR-384 & PIWIL4 & LGG-15, HGG-15 & Proliferation, invasion, migration, apoptosis & [53] \\
\hline & - & mTOR & 37 glioma & Proliferation, invasion, migration & [54] \\
\hline & - & - & LGG-5, HGG-14 & Proliferation, apoptosis & [55] \\
\hline ECONEXIN $\uparrow$ & miR-411-5p & TOP2A & 40 glioma & Proliferation & [56] \\
\hline FER1L4 $\uparrow$ & - & - & LGG-335, HGG-21 & Proliferation, invasion, apoptosis & [57] \\
\hline FOXD3-AS1 $\uparrow$ & - & FOXD3 & LGG-13, HGG-31 & Proliferation, invasion, migration & [58] \\
\hline $\mathrm{FTX} \uparrow$ & miR-342-3p & AEG1 & $\begin{array}{l}\text { LGG-76, HGG-81 from data base; } \\
\text { LGG-11, HGG-11 }\end{array}$ & Proliferation, invasion & [59] \\
\hline \multirow{6}{*}{$\mathrm{H} 19 \uparrow$} & miR-140 & iASPP & 28 glioma & Proliferation & {$[60]$} \\
\hline & miR-675 & - & LGG-15, HGG-20 & Proliferation & [61] \\
\hline & miR-675 & CDK6 & LGG-4, HGG-4 & Proliferation & [62] \\
\hline & - & MDR, MRP, ABCG2 & TMZ-Sensitive-44, TMZ-Resistant-25 & TMZ-Resistance & [63] \\
\hline & miR-29a & - & 30 glioma & Angiogenesis & [64] \\
\hline & miR-29a & VASH2 & LGG-5, HGG-5 & Angiogenesis & [65] \\
\hline
\end{tabular}


Table 1. Cont

\begin{tabular}{|c|c|c|c|c|c|}
\hline IncRNA & Target miRNA & Genes and/or Pathways & Samples & Biological Processes & References \\
\hline \multirow{6}{*}{ HOTAIR $\uparrow$} & miR-148b-3p & - & $\begin{array}{l}26 \text { astrocytoma ( } 7 \text { grade II, } 19 \text { grade } \\
\text { III), } 50 \text { oligodendroglioma ( } 38 \text { grade } \\
\text { II, } 12 \text { grade III) and } 81 \text { GBM }\end{array}$ & Cell growth, proliferation, invasion & {$[66]$} \\
\hline & miR-148b-3p & ZO-1, OCLN, CLDN5, USF1 & - & Angiogenesis & [67] \\
\hline & - & BRD4 & 17 glioma & Proliferation, invasion, migration, apoptosis & [68] \\
\hline & $\mathrm{miR}-326$ & $\begin{array}{l}\text { FGF1, PI3K/AKT and MEK1/2 } \\
\text { signal pathways }\end{array}$ & LGG-6, HGG-6 & Proliferation, invasion, migration & [69] \\
\hline & - & - & 67 glioma & Proliferation, invasion, migration & [70] \\
\hline & - & VEGFA & - & Angiogenesis & [71] \\
\hline HOTTIP $\downarrow$ & - & BRE, cycA and CDK2, p53 & LGG-37, HGG-48 & Proliferation, apoptosis & [72] \\
\hline \multirow{2}{*}{ HOXA11-AS $\uparrow$} & miR-214-3p & EZH2 & 45 glioma & Proliferation, migration, invasion & [73] \\
\hline & miR-140-5p & - & LGG-13, HGG-30 & Proliferation, invasion, migration, apoptosis & [74] \\
\hline HOXA11-AS3 $\uparrow$ & - & - & LGG-24, HGG-23 & Proliferation & [75] \\
\hline \multirow[b]{2}{*}{ HULC $\uparrow$} & - & - & LGG-10, HGG-60 & Proliferation, patients overall survival & [76] \\
\hline & - & $\begin{array}{l}\text { Survivin, c-Myc, Cyclin A/D1/E, } \\
\text { p-Rb, Skp-1/2, CDK2/4 and } \\
\text { EZH2, Bcl-2/Bax, caspase-3/8 }\end{array}$ & LGG-30, HGG-90 & $\begin{array}{c}\text { Proliferation invasion, migration, angiogenesis, } \\
\text { adhesion }\end{array}$ & [77] \\
\hline Linc-OIP5 $\uparrow$ & - & Yap, Notch & LGG-69, HGG-98 & Proliferation, migration & [78] \\
\hline $\operatorname{lnc} 00462717 \downarrow$ & - & MDM2 & LGG-16, HGG-64 & Proliferation, migration, apoptosis & [79] \\
\hline \multirow{3}{*}{ MALAT1 $\uparrow$} & miR-140 & Nuclear factor YA & LGG-8, HGG-8 & $\begin{array}{l}\text { Proliferation, chemosensitivity, BTB } \\
\text { permeability }\end{array}$ & [80] \\
\hline & miR-101 & STMN1, RAB5A, ATG4D & 32 glioma & Proliferation, migration, autophagy & [81] \\
\hline & - & CCND1, MYC & LGG-37, HGG-37 & Proliferation, apoptosis & [82] \\
\hline \multirow{3}{*}{ MALAT1 $\downarrow$} & - & Ki-67, MMP2, MAPK & LGG-32, HGG-100 & Proliferation & [83] \\
\hline & miR-155 & FBXW7 & LGG-21, HGG-45 & Proliferation, correlates with survival & [84] \\
\hline & miR-203 & TS & 180 glioma & Chemoresistance & [85] \\
\hline MDC1-AS $\downarrow$ & - & $\mathrm{MDC1}, \mathrm{CycB1/CDK2}$ & 15 glioma & Proliferation & {$[86]$} \\
\hline MEG3 $\downarrow$ & miR-19a & PTEN & 40 glioma & Proliferation, apoptosis & [87] \\
\hline MIR155HG $\uparrow$ & $\begin{array}{l}\text { miR-155-5p, } \\
\text { miR-155-3p }\end{array}$ & PCDH7, PCDH9, Wnt/B-catenin & 225 glioma & Proliferation & {$[88]$} \\
\hline $\operatorname{miR210HG\uparrow }$ & - & - & 28 glioma & Proliferation & [89] \\
\hline MVIH $\uparrow$ & - & - & LGG-57, HGG-70 & Proliferation, invasion, migration & [90] \\
\hline
\end{tabular}


Table 1. Cont

\begin{tabular}{|c|c|c|c|c|c|}
\hline IncRNA & Target miRNA & Genes and/or Pathways & Samples & Biological Processes & References \\
\hline \multirow{5}{*}{ NEAT1 $\uparrow$} & miR-181d-5p & SOX5 & - & BTB & [91] \\
\hline & - & - & LGG-23, HGG-71 & Proliferation, invasion, migration & [92] \\
\hline & miR-107 & CDK6 & LGG-5, HGG-24 & Proliferation, invasion, migration & [93] \\
\hline & miR-449b-5p & c-met & LGG-10, HGG-5 & Proliferation, invasion, migration, apoptosis & [94] \\
\hline & let-7e & $\begin{array}{l}\mathrm{PI} 3 \mathrm{~K} / \mathrm{AKT} / \mathrm{mTOR}, \mathrm{MEK} / \mathrm{ERK} \\
\text { pathways }\end{array}$ & LGG-60, HGG-60 & Proliferation & [95] \\
\hline POU3F3 $\uparrow$ & - & - & LGG-37, HGG-45 & Proliferation, angiogenesis & [96] \\
\hline \multirow{4}{*}{ PVT1 $\uparrow$} & - & - & 98 glioma & $\begin{array}{l}\text { Patients survival, chemotherapy, radiotherapy } \\
\text { response }\end{array}$ & [97] \\
\hline & miR-488-3p & MEF2C & LGG-9, HGG-10 & Proliferation, migration, invasion & [98] \\
\hline & $\mathrm{miR}-186$ & Atg7, Beclin1 & - & Proliferation, migration, angiogenesis & [99] \\
\hline & miR-190a-5p & EZH2, JAGGED1 & LGG-40, HGG-40 & Cell cycle, apoptosis & [100] \\
\hline SPRY4-IT1 $\uparrow$ & - & - & LGG-73, HGG-90 & Proliferation, invasion, migration, apoptosis & [101] \\
\hline TP53TG1 $\uparrow$ & - & - & LGG-12, HGG-12 & Proliferation, invasion, migration, apoptosis & [102] \\
\hline TP73-AS1 $\uparrow$ & $\operatorname{miR}-142$ & HMGB1 & LGG-26, HGG-21 & Proliferation, invasion & [103] \\
\hline TSLC1-AS1 $\downarrow$ & - & TSLC1 & LGG-37, HGG-28 & Proliferation, migration, invasion & [104] \\
\hline TUG1 $\uparrow$ & miR-144 & HSF2, ZO-1, OCLN, CLDN5 & LGG-5, HGG-5 & Angiogenesis & [105] \\
\hline \multirow{2}{*}{ TUG1 $\downarrow$} & - & BCL-2, CASP3, CASP9 & LGG-57, HGG-63 & Proliferation, apoptosis & [106] \\
\hline & miR-26a & PTEN & LGG-9, HGG-11 & Proliferation, apoptosis & [107] \\
\hline TUSC7 $\downarrow$ & miR-23b & TUSC7 & LGG-19, HGG-20 & Proliferation, apoptosis, correlates with survival & [108] \\
\hline \multirow{3}{*}{ UCA1 $\uparrow$} & miR-122 & - & 63 glioma & Proliferation, migration, invasion, apoptosis & [109] \\
\hline & - & cycD1 & LGG-22, HGG-42 & Proliferation & [110] \\
\hline & miR-182 & iASPP & LGG-27, HGG-49 & Proliferation, migration, invasion, apoptosis & [111] \\
\hline \multirow{5}{*}{ Xist $\uparrow$} & miR-137 & Rac1 & LGG-9, HGG-21 & Proliferation & [112] \\
\hline & miR-137 & XCR7, ZO-2, FOXC1 & - & Angiogenesis & [113] \\
\hline & miR-152 & - & Astrocytoma & Proliferation, migration, invasion, apoptosis & [114] \\
\hline & miR-429 & - & 157 glioma & Proliferation, migration, invasion, angiogenesis & [115] \\
\hline & $\operatorname{miR}-29 \mathrm{c}$ & MGMT, SP1 & LGG-33, HGG-36 & Chemosensitivity & [116] \\
\hline ZEB1-AS1 $\uparrow$ & - & $\begin{array}{l}\text { CycD1 and CDK2 ZEB1, MMP2, } \\
\text { MMP9, CDH2, Integrin- } \beta 1\end{array}$ & LGG-37, HGG-45 & Proliferation, invasion, migration, apoptosis & [117] \\
\hline ZFAS1 $\uparrow$ & - & Notch signaling pathway & 46 glioma & $\begin{array}{c}\text { Proliferation, migration, invasion, disease } \\
\text { prognosis }\end{array}$ & [118] \\
\hline
\end{tabular}




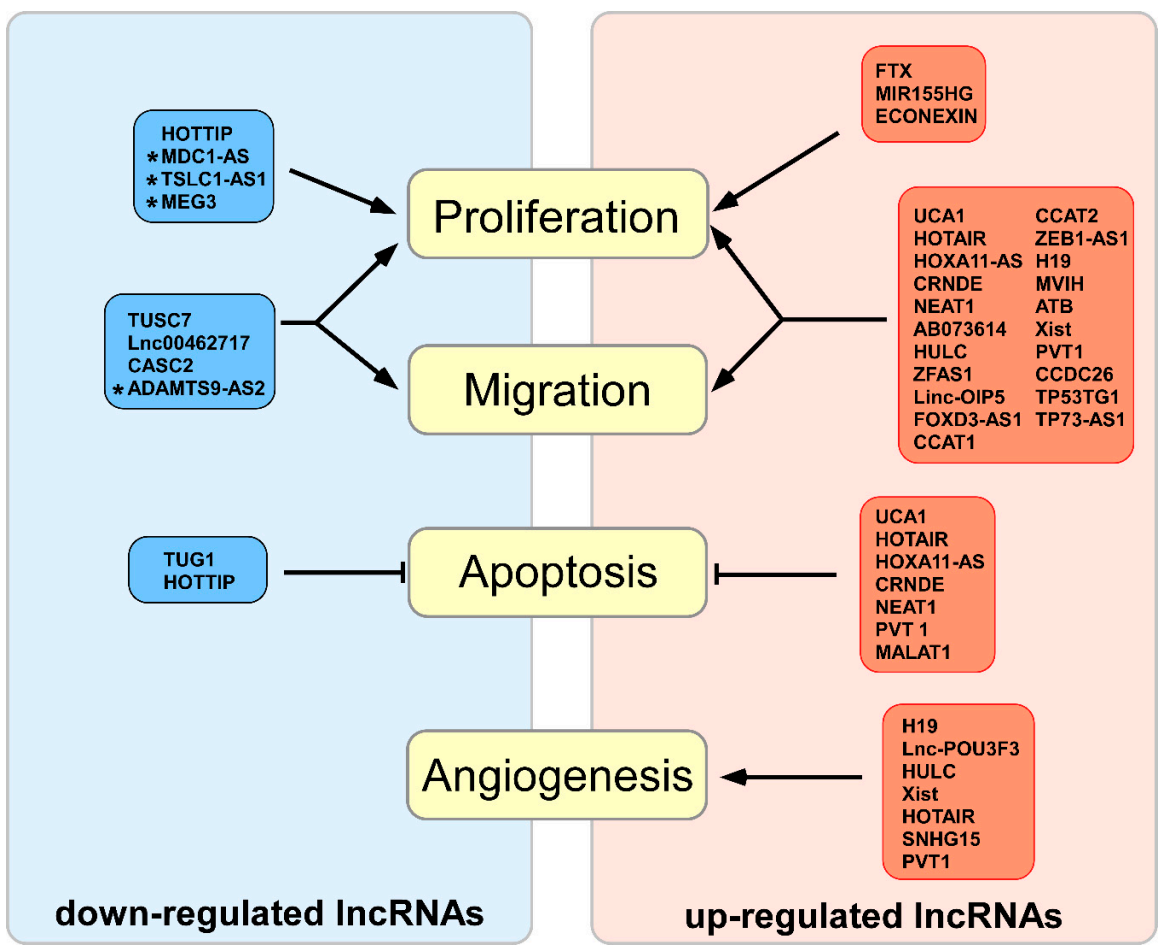

Figure 1. Up-regulated and down-regulated long non-coding RNAs in glioma and their influence on the biological processes. Red indicates up-regulated RNAs in glioma, and blue indicates down-regulated RNAs in glioma. Arrows indicate increased activity of the process; hammerhead arrows indicate decreased activity of the process; asterisk indicates poorly characterized lncRNAs.

\subsubsection{AB073614 lncRNA}

The up-regulation of lncRNA AB073614 is associated with a poor survival in glioblastoma patients. A suppressed expression of AB073614 reduces cell migration by increasing e-cadherin and decreasing vimentin expression. All this data shows the importance of AB073614 in EMT process [38,40]. In 2017, Wang revealed that $\mathrm{AB} 073614$ alters proliferation via the PI3K/Akt pathway and is able to increase the expression MMP9 (Matrix Metallopeptidase 9), Bcl-2 while decrease the expression of Bax [39].

\subsubsection{ATB, H19, ZEB1-AS lncRNAs}

Lnc-RNA ZEB1-AS1 regulates the expression of cyclin D, CDK2 (Cyclin Dependent Kinase 2), ZEB1 (Zinc Finger E-Box Binding Homeobox 1), MMP2, MMP9, N-cadherin and integrin- $\beta 1$ genes. This proves that ZEB1-AS1 regulates the EMT processes and is involved in proliferation, apoptosis and metastasis of glioma, but data about the exact signaling pathway is lacking [117]. Zhao et al. also showed that elevated $\mathrm{H} 19$ expression modulated glioma growth by targeting $i A S P P$ via miR-140 [60]. Zhang et al. demonstrated that $\mathrm{H} 19$ role in proliferation is mediated by miR-675, which is encoded in H19 1 exon [61] and directly suppress Cyclin Dependent Kinase 6 (CDK6) expression [62]. An increased expression of lncRNA ATB positively correlates with glioma grade and negatively with the survival rate of glioma patients. It was shown that lncRNA ATB is directly targeted by miR-200a, which affects the expression of TGF- $\beta 2$. TGF- $\beta 2$, in turn, activates the MAPK signaling pathway [119]. In addition, the down-regulation of ATB in vivo suppressed tumor growth [42]. MiR-152 is another miRNA down-regulated by H19 [120]. This leads to the activation of tumor proliferation and invasion in vitro and in vivo [42].

\subsubsection{CCAT1, CCAT2, CCND2-AS1 lncRNAs}

LncRNA CCAT1 is involved in the cell proliferation process and is a target of miR-410 [47]. The expression of miR-410 is suppressed in glioma tissue, and this leads to the activation of the MET/Akt 
signaling pathway [121]. However, there is no evidence that CCAT1 is involved in the regulation of met expression. Later, in 2017, another group announced that CCAT1 enhances Fibroblast Growth Factor Receptor 3 (FGFR3) and Platelet-Derived Growth Factor Receptor A (PDGFRA) expression by targeting miR-181b. Both growth factors activate MAPK/ERK1 signaling pathways [122]. The ability of CCAT1 to promote tumor growth was also shown in vivo [48]. An increased expression of CCAT2 and CCND2-AS1 induces proliferation, cell cycle progression and migration via the $\mathrm{Wnt} / \beta$-catenin signaling pathway and downregulation of CCAT2 expression significantly reduces brain tumor growth in vivo [49,51].

\subsubsection{CRNDE lncRNA}

The lncRNA CRNDE is highly up-regulated in glioma tissue, and promotes proliferation, migration and invasion processes [52]. The capability of CRNDE to induce gliomagenesis has been tested in vivo, and it was shown that CRNDE acts via the mTOR signaling pathway, involving myc, cycline-D1, p53 and Phosphatase and Tensin homolog (PTEN) genes [54]. CRNDE is also a target of miR-384, and both of them regulate the level of PIWIL4 protein. PIWIL4, in turn, promotes progression by inducing phosphorylation of STAT3, the main member in PI3K/Akt1/IL-6/STAT3 pathway [53]. In 2017, it was determined that an up-regulated expression of CRNDE induces EGFR (Epidermal Growth Factor Receptor) activation, resulting in poor survival in glioma patients and apoptosis inhibition through increased Bcl2/Bax (BCL2 Associated X) ratio [55].

\subsubsection{CCDC26, FER1L4, miR210HG, MVIH, SPRY4-IT1, TP53TG1, IncRNAs}

CCDC26 is a newly identified lncRNA the expression of which is up-regulated in glioma tissue. CCDC26 directly targets miR-203, and this effect was shown in vitro and in vivo [50]. LncRNAs FER1L4, TP53TG1, SPRY4-IT1, miR210HG, MVIH are highly expressed in glioma and their elevated expression is associated with a poor prognosis. They activate the proliferation and invasion processes together with an inhibition of apoptosis via yet undetermined pathways $[57,89,90,101,102]$.

\subsubsection{ECONEXIN, TP73-AS1, Xist lncRNAs}

An increased expression of lncRNA TP73-AS1 is associated with poor survival in patients, and the down-regulation of TP73-AS1 inhibited the proliferation and invasion processes together with High-Mobility Group Box 1 (HMGB1) expression, which plays an important role in many diseases including cancer by targeting miR-142 [103,123,124]. A decreased expression of miR-142 correlates with increased levels of Ras-related C3 botulinum toxin substrate 1 (Rac1), which activates multiple pathways [125]. LncRNA ECONEXIN is up-regulated in glioma tissue and promotes cell proliferation via sponging miR-411-5p and altering the expression of topoisomerase 2 alpha (TOP2A) gene [56]. LncRNA Xist also regulates the expression of Rac1 by inhibiting the expression of miR-137 [112]. Another study provided evidence that direct Xist binding to miR-152 promotes the formation of glioma [114]. Xist also binds miR-29 and miR-429 [115,116]. The fact that Xist binds to many miRNAs proves it's importance in gliomagenesis, however, the exact pathways are still unclear.

\subsubsection{FOXD3-AS1, Linc-OIP5, ZFAS1lncRNAs}

In 2017, an lncRNA named ZFAS1 was detected in glioma tissue. ZFAS activates cell proliferation, invasion and migration processes by activating EMT and Notch signaling pathways. Gao et al. also showed that ZFAS1 activates the EMT pathway [118]. There is no data about the interaction of ZFAS1with any miRNAs yet. Linc-OIP5 is another newly identified long non-coding RNA, up-regulated in glioma tissue and positively correlating with a glioma grade. It induces proliferation and migration processes through Notch-1, yes-associated protein 1 (YAP), Jagged-1 (Jag-1) and hairy and enhancer of split-1 (Hes-1) and the down-regulation of its expression reduces tumor growth in vivo [78]. LncRNA FOXD3-AS1 is involved in cell proliferation, migration and invasion processes, is associated with a poor prognosis and correlates with a glioma grades. The overexpression of LncRNA 
FOXD3-AS1 reduces the level of transcription factor Forkhead Box D3 (FOXD3), which takes part in the processes of differentiation, proliferation, migration and apoptosis [58].

\subsubsection{FTX lncRNA}

The newly discovered lncRNA FTX initiates the proliferation process by binding to miR-342-3p, which, in turn, directly binds Astrocyte Elevated Gene-1 (AEG-1) [59]. AEG-1 is an important player in the carcinogenic process in diverse organs and tissues and can act through multiple pathways, including PI3K/Akt, NF- $\kappa B$, Wnt/ $\beta$-catenin and MAPK [126]. It makes FTX a very promising target for novel treatments of glioma. However, there is no data about miR-342p expression in glioma tissue [127].

\subsubsection{HOTAIR, HOXA11-AS, UCA1 IncRNAs}

UCA1, HOTAIR and HOXA11-AS are the most studied up-regulated lncRNAs. UCA1 is involved in the proliferation and migration processes, and its expression positively correlates with overall patient survival. It was shown that UCA1 activates the expression of inhibitor of Apoptosis Stimulating Protein of p5 (iASPP) gene by inhibiting the expression of miR-182 [111]. In normal brain tissue, miR-182 regulates apoptosis, proliferation and migration processes by inhibiting the expression of iASPP [128]. At the same time, Sun et al. also showed that elevated levels of UCA1 down-regulate miR-122 [109]. In turn, decreased levels of miR-122 are associated with a tumor proliferation, invasion and migration via Wnt/ $\beta$-catenin signaling pathway [129-131]. In addition, inhibition of UCA 1 expression using si-RNA in U87 and U251 cell lines promoted the expression of cyclin D1 [110]. Several studies showed that lncRNA HOTAIR is a target for miR-326 [69] and miR 148b-3p [66]. The suppressed expression of HOTAIR together with mimics of miR-326 had the strongest inhibitory effect on proliferation, migration and invasion processes in U87 and U251 cell lines. It was shown that a possible target of HOTAIR/miR-326 is FGF, which activates the PI3K/AKT signaling pathway [132]. The involvement of HOTAIR and miR-326 in gliomagenesis was also shown in nude mice, where it suppressed tumor growth and prolonged overall survival $[69,70]$. Besides that the inhibition of HOTAIR expression induces apoptosis, it was also shown that the BET (Bromodomain and Extra-Terminal) family protein BRD4 regulates HOTAIR expression [68]. The decreased expression of lncRNA HOXA11-AS induces a cell cycle arrest and initiates apoptosis in HG44 and U251 cell lines. HOXA11-AS is targeted by miR-140-5p [74], which regulates cell proliferation and invasion via the VEGFA/MMP-2 signaling pathway [133]. The microarray data revealed that there are about 500 genes correlated with a HOXA11-AS3 expression. The suppressed expression of HOXA11-AS3 inhibited the growth of the glioma tumor in nude mouse [75]. Recently, Xu et al. showed that HOXA11-AS decreases the expression of miR-214-3p, which directly targets Enhancer of Zeste 2 polycomb repressive complex 2 subunit (EZH2), a component of many signaling pathways, including Wnt/ $\beta$-catenin, MAPK and Notch [73].

\subsubsection{HULC IncRNA}

Despite the fact that HULC is one of the most intensively investigated long non-coding RNAs, due to its association with cancer, it's up-regulation in glioma was shown only in 2016 [76,77]. It was demonstrated that HULC activates proliferation, adhesion and migration processes together with an EMT process through the PI3K/Akt/mTOR signaling pathway [77].

\subsubsection{MIR155HG lncRNA}

The increase of LncRNA MIR155HG expression initiates an epithelial mesenchymal transition (EMT). It promotes the tumor cell proliferation process in vitro (U87, U251, and primary GBM cells) and in vivo (mouse model system). MIR155HG is a primary RNA for miR-155-3p and miR-155-5p, which targets protocadherin -9 and -7 , respectively. Protocadherin- 9 and -7 , in turn, function as tumor suppressors by inhibiting the Wnt/ $\beta$-catenin signaling pathway $[88,134]$. 


\subsubsection{NEAT1 lncRNA}

An overexpression of IncRNA NEAT1 in glioma tissue positively correlates with glioma grade [94], and a lower NEAT1 expression correlates with longer survival of glioma patients [92]. NEAT1 activates proliferation, migration and invasion processes and deregulates apoptosis possibly by interacting with miR-449b-5p, which in turn activates the met oncogene. The involvement of NEAT1/miR-449-5p/met in tumorigenesis was also shown in vivo [94]. In addition, a negative correlation between NEAT1 and miRNA let-7e expression was observed. NEAT1 is a direct target of let-7e and activates cell proliferation via PI3K/AKT/mTOR and MEK/ERK pathways [95]. NEAT1 also activates met expression via silencing miR-449b-5p. Met is a well-known oncogene, which activates MAPK/ERK and $\mathrm{Akt} / \mathrm{mTOR}$ signaling pathways [94]. This is the only study proving the involvement of miR-449b-5p in gliomagenesis. Recently, Yang et al. discovered that NEAT1 increases Cyclin Dependent Kinase 6 (CDK6) expression via miR-107 in the U87 cell line [93].

\subsubsection{PVT I lncRNA}

Yang et al. demonstrated an increased lncRNA PVT I expression in glioma tissue. They showed that PVT I expression positively correlates with poor outcome and alters the expression of EZH2. This lncRNA also regulates cell cycle and apoptosis in vitro and in vivo $[97,100]$. PVT I, by binding to miR-190a-5p and miR-488-3p, is able to regulate the expression of Myocyte Enhancer Factor 2C (MEF2C) and JAGGED1. It is known that the JAGGED1-NOTCH signaling pathway is critical for glioma proliferation [98].

\subsection{Down-Regulated IncRNAs in Biological Glioma Processes}

The down-regulated IncRNAs function as tumor suppressors and inhibit cell cycle and proliferation. Deregulation of the tumor suppressors is common in all types of cancer.

\subsubsection{ADAMTS9-AS2, MDC1-AS, MEG3, TSLC1-AS1 lncRNAs}

Little is known about lncRNAs MEG3, MDC1-AS, TSLC1-AS1 and ADAMTS9-AS2. MEG3 activates cell proliferation process through the PTEN pathway via miR-19a [87]. A decreased expression of lncRNA MDC1-AS induces cell proliferation via MDC1, but a detailed mechanism remains to be revealed [86]. TSLC1-AS1 is an antisense regulator of the suppressor gene Tumor Suppressor in Lung Cancer 1 (TSLC1). Therefore, the exact pathway by which TSLC1 suppresses cell growth is still unknown [104]. In addition, not much is known about ADAMTS9-AS2, the expression of which is down-regulated in glioma and correlates with a glioma grade. It was shown that an over-expression of ADAMTS9-AS2 inhibits cell migration and invasion processes [41].

\subsubsection{CASC2 IncRNA}

Liao et al. showed that CASC2 negatively correlates with glioma grade and overall survival in patients. Their data shows that the expression of CASC2 influenced the TMZ resistance through the CASC2/miR181a/PTEN pathway [44]. Wang et al. also showed that CASC2 suppresses Wnt/ $\beta$-catenin pathway [45]. Another study showed that CASC2 is a target of miR-21 [43], which is frequently overexpressed in tumor cells [135] and takes part in proliferation, migration and invasion processes, possibly through the p53 pathway [136]; but there is no data about the direct involvement of CASC2 in this pathway.

\subsubsection{HOTTIP lncRNA}

The expression of the lncRNA HOTTIP is mainly down-regulated in glioma. However, its overexpression inhibited proliferation and induced apoptosis in vitro. Also, a negative correlation between HOTTIP and BRE (one of the BRCA1-A complex subunit) levels was observed [72]. BRE, in turn, plays an essential role in preventing replicative and DNA damage-induced premature 
senescence [137]. The decrease of BRE expression, in addition, decreases the expression of cyclin $A$ and $C D K 2$ and increases the expression of $p 53$ [72]. Interestingly, another study showed that under hypoxic conditions there is an overexpression of HOTTIP RNA, and the HOTTIP expression in glioma samples with metastasis was approximately 4 folds higher than in glioma samples without metastasis. Zhang et al. demonstrated, that HOTTIP contributes to epithelial-mesenchymal transition (EMT) and metastasis in glioma by targeting miR-101 and in turn elevates the amount of ZEB1 mRNA, which is a direct target of miR-101 [138].

\subsubsection{Lnc00462717 lncRNA}

Low Lnc00462717 expression negatively correlates with the expression of Mouse double minute 2 (MDM2). Bioinformatics analysis revealed that Lnc00462717 is upstream of MDM2, and it directly targets MDM2 transcription. Lnc00462717 suppresses cell proliferation, survival and migration processes possibly via the MDM2/MAPK pathway, but the specific mechanisms are yet unknown. There is no data about the interactions of Lnc00462717with miRNAs or any other target genes [79].

\subsubsection{MALAT1 lncRNA}

The controversy regarding the expression pattern of lncRNA MALAT1 in gliomas may be associated with the complexity of non-coding RNA biology and the heterogeneity of glioma tumors. Three studies showed that the expression of MALAT1 is up-regulated in glioma, and two-that the expression is down-regulated. Based on the data, the expression of MALAT1 is down-regulated in glioma tissue and cell lines. Besides, high levels of MALAT1 correlate with better overall survival of patients with glioma. It was also shown that MALAT1 negatively regulates miR-155 expression. One of the validated targets of miR-155 is circular RNA F-box/WD-repeat-containing protein (7FBXW7). According to the results, MALAT1 suppresses the viability of the glioma cells by down-regulating miR-155 and promoting the expression of FBXW7 [84]. Han et al. also measured the expression of MALAT1 in glioma specimens and glioma cell lines. In accordance to their data, the expression of MALAT1 is higher in non-cancerous brain tissues, whereas there were no differences between the grades. An overexpression of MALAT1 is associated with suppressed of glioma cells. This effect was also shown in vivo. Their results revealed that the overexpression of MALAT1 suppressed the activation of the MAPK pathway [83].

On the other hand, referring to Xiang et al.'s results, MALAT1 is highly expressed in glioma tissue and in glioma cell lines [82]. The decrease of MALAT1 expression suppressed the growth rate of glioma cells and induced apoptosis. They also showed that the decreased expression of MALAT1 down-regulated the expression of cycline D1 and myc [82]. Fu et al. also detected the increase of MALAT1 expression. They concluded that MALAT1 is able to induce proliferation and autophagy in the cells and targets miR-101, which, in turn, regulates the expression of Stathmin 1 (STMN1), RAB5A and Autophagy Related 4D Cysteine Peptidase (ATG4D). The increase of miR-101 expression or decrease of MALAT1 expression reduces the expression of autophagy genes [81]. A precise classification of glioma specimens on a molecular level could possibly resolve this controversy.

\subsubsection{TUG1 lncRNA}

It was shown that the decreased expression of TUG1 correlates with the up-regulation of miR-26a. One of the validated targets of miR-26a is PTEN [139]. Using U251 and SHG-44 glioma cell lines, it was shown that TUG1 regulates PTEN expression by sponging miR-26a [107]. In another study, it was identified that the up-regulation of TUG1 activates caspases by inhibiting the expression of $B c l-2$, suggesting its involvement in regulation of programmed cell death and immune response [106].

\subsubsection{TUSC7 lncRNA}

The expression of TUSC7 is down-regulated in glioma tissue and negatively correlates with the overall survival of the patients and expression of miR-23b [108]. In addition, Jiang et al. showed 
that the expression of miR-23b regulates the PI3K/Akt signaling pathway [140]. However, there is no evidence of the direct involvement of TUSC7 in PI3K/Akt pathway regulation. Overall, the large list of lncRNAs that are aberrantly expressed in glioma tissue shows its importance for many processes involved in glioma development. These lncRNAs are a potential tool for accurate diagnosis, individualized treatment and prognosis. Furthermore, a deregulated expression of lncRNAs according to chemosensitivity, angiogenesis and brain-tumor-barrier status has been observed and will be discussed in later chapters.

\section{3. miRNAs Involved in Gliomagenesis in Association with lncRNAs}

As miRNAs have been studied longer than lncRNAs, a lot of data has been accumulated about miRNA target genes and signaling pathways. After the discovery of lncRNAs, there are still links missing between processes controlled by miRNA and lncRNA. Not all of these pathways have been linked to associated lncRNAs. Here we summarize the data about signaling pathways and targeted genes which are regulated by miRNAs associated with lncRNAs (Figure 1). According to the target genes, miRNAs and lncRNAs can be grouped into three main signaling pathways: PI3K/Akt/mTOR, Wnt $/ \beta$ catenin and Notch. Some of the miRNAs/lncRNAs are able to regulate more than one signaling pathway. The network of these ncRNAs is more complicated, but it makes them promising prognostic and/or predictive biomarkers (Figure 2).

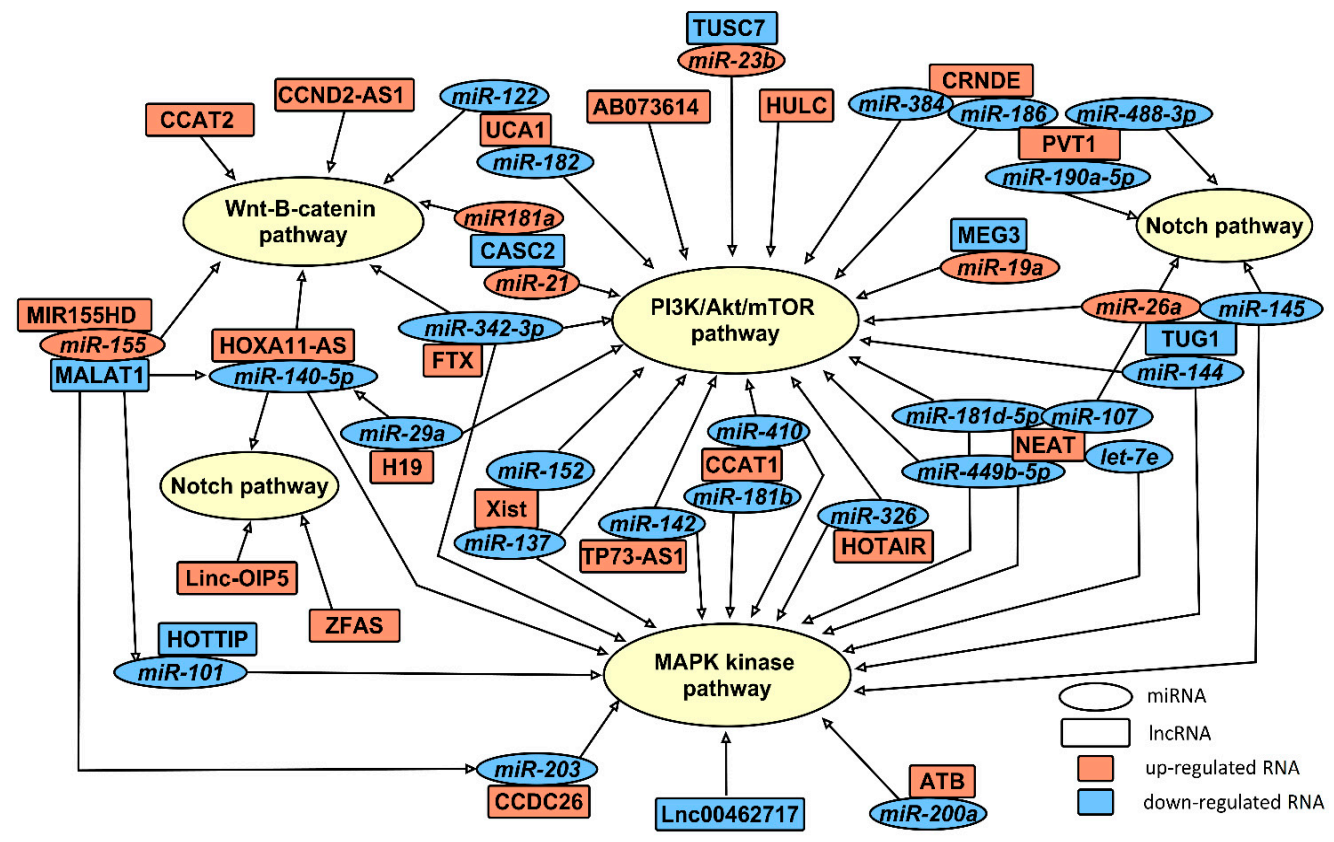

Figure 2. LncRNA and miRNA pathway regulation network. Rectangles represent long-non-coding RNA and ovals-miRNA which are the target/targets of lncRNA. Red color indicates up-regulates RNA in glioma, and blue-down-regulated RNA in glioma. Arrows indicate the signal transduction pathway affected.

\subsection{1. let-7e}

The dual-luciferase assay results showed a potential binding region between NEAT1 lncRNA and let-7e miRNA. An expression of let-7e is significantly down-regulated in GBM tissues and GBM cell lines, compared to healthy brain tissues and normal human astrocytes. Moreover, let-7e expression negatively correlates with glioma grade. A CCK-8 assay demonstrates that glioma stem cell proliferation is significantly lower in the let-7e overexpression group, thus suggesting that let-7e functions as a tumor suppressor. It was showed that NRAS may be involved in NEAT1/let-7e-dependent progression of glioma stem cells [95]. 


\subsection{2. $\mathrm{miR}-19 \mathrm{a}$}

LncRNA MEG3 regulates the cell proliferation process through PTEN and miR-19a [87]. Sun et al. demonstrated that miR-19 expression positively correlates with glioma tumor grade. Down-regulation of miR-19 expression inhibits proliferation, invasion, induces cell cycle G1 arrest and apoptosis via Runt Related Transcription Factor 3 (RUNX3) expression regulation by binding to its 3'-UTR and represses the $\beta$-catenin/Transcription Factor 4 (TCF4) transcription activity in LN229 and U87 cells [141]. Bioinformatics analysis showed that Peroxisome proliferator-activated receptor alpha $(P P A R \alpha)$ is another target of miR-19a, and a low PPAR $\alpha$ expression level is associated with worse outcomes in clinical glioma patients. PPAR $\alpha$ is down-regulated by E2F1/miR-19a signaling in glioma cells. In addition, it was found that miR-19a expression is significantly higher in high grade glioma samples when compared to low grade glioma samples. Down-regulation of miR-19a is associated with suppressed glioma cell proliferation, invasion and aerobic glycolysis [142].

\subsection{3. $\mathrm{miR}-21$}

Another study showed that CASC2 is a target of miR-21 [43], which is frequently overexpressed in tumor cells [135] and takes part in stimulation of proliferation, migration and invasion processes possibly through p53 pathway [136]. Luo et al. study results show that a high miR-21 expression significantly promotes the migration and invasion of glioma cells through the miR-21/Sox $2 / \beta$-catenin signaling pathway [143]. Chen el al., by analyzing microarray gene expression data and clinical information of glioma patients, identified seven miRNAs (miR-7, miR-15b, miR-21, miR-124a, miR-129, miR-139, miR-218) with prognostic potential [144]). Moreover, miR-21 is up-regulated in glioma vessels and subsets of glioma cells. The expression of miR-21 is co-localized in vasculature and in tumor cells bordering necrotic areas together with angiogenesis-associated markers HIF-1 and VEGF [145]. Furthermore, evidence shows that miR-21 increases the resistance of human glioma cells to carmustine (BCNU) by decreasing Sprouty RTK Signaling Antagonist 2 (Spry2) protein levels [146].

\subsection{4. miR-23b}

LncRNA TUSC7 is related to miR-23b. Bioinformatics analysis indicated that TUSC7 specifically binds to miR-23b, which was up-regulated in glioma and negatively correlates with the expression of TUSC7 [108]. Jiang et al. demonstrated that Mitochondrial transcription factor A (TFAM), which plays a key role in mitochondrial DNA replication, transcription and inheritance, is the direct target of miR-23b. Moreover, miR-23b expression was significantly lower in glioma when compared to normal tissue and negatively correlated with the glioma malignancy grade. A high miR-23b expression also inhibits cell proliferation, cell cycle progression, migration and colony formation of U251 glioma cells [140].

\subsection{5. $\mathrm{miR}-26 \mathrm{a}$ and $\mathrm{miR}-145$}

LncRNA TUG1 also regulates the expression of miR-145. Its expression is decreased in glioblastoma tumor tissue and glioma stem cells and negatively correlates with glioma grade. On the other hand, the up-regulation of miR-145 inhibited cell proliferation, invasion, induced G1/S transition arrest in vitro and suppressed xenograft growth in vivo [147]. MiR-145 is one of the miRNAs which directly regulate the expression of Platelet Derived Growth Factor Receptor Beta (PDGFRB), neuronal markers, $\beta$ III-tubulin, neuronal nuclei antigen $(\mathrm{NeuN})$, Microtubule Associated Protein 2 (MAP2), BCL2 Interacting Protein 3 (BNIP3) and the Notch signaling pathway. It regulates microvascularisation, neurogenesis and cell proliferation [148-150]. Besides that, it was shown that the expression of miR-26a negatively correlates with TUG1. Studies have shown that miR-26a expression is up-regulated in glioblastoma. MiR-26a also regulates the expression of critical signaling genes such as PTEN, RB1 and $M A P 3 K 2 / M E K K 2$, promotes tumor growth and inhibits JNK-dependent apoptosis in vivo [151]. 
All these results show the importance of TUG1 and associated miRNAs in glioma formation and progression processes.

\subsection{6. $\mathrm{miR}-29$}

An increased expression of miR-29a in primary GBM cells is associated with lncRNAs Xist and H19. miR-29a, by targeting Induced myeloid leukemia cell differentiation protein (MCL1), increases apoptosis in GICs cells [152]. Xi et al. demonstrated that miR-29a is down-regulated in glioblastoma stem cells when compared to non-glioblastoma stem cells. A high miR-29a expression in GSCs inhibited cell proliferation, migration, invasion and promoted apoptosis by binding to its direct target Quaking gene isoform 6 (QKI-6) [153]. Xiao et al. showed that miR-29c expression was significantly down-regulated in the majority of glioma tumor samples compared to normal brain tissues. Moreover, a high miR-29c expression level was associated with better overall survival in glioma patients and increased sensitivity to temozolomide. miR-29c, by indirectly targeting MGMT through Specificity protein 1 (Sp1), inhibited cell growth and promoted apoptosis in U251/TR cell lines in vitro and in vivo [154].

\subsection{7. $\mathrm{miR}-101$}

It was shown that the expression of miR-101 is associated with two lncRNAs: MALAT1 and HOTTIP. miR-101 epigenetically suppresses the expression of LIM domain only 3 (LMO3) by inhibiting the binding of Upstream stimulatory factor 1 (USF) and Myeloid Zinc Finger 1 (MZF1) to the LMO3 promoter and induces cell apoptosis in U251 glioma cells [155]. An elevated expression of this miRNA inhibits proliferation and migration of glioma cell in vitro, as well as the growth of glioma tumor in vivo via regulation of cyclooxygenase-2 (COX-2) and transcription factor SOX9 expression [156,157]. MiR-101 is also essential for chemotherapy. It was shown that miR-101 expression is associated with sensitivity to temozolomide in TMZ-resistant GBM cells through down-regulation of glycogen synthase kinase $3 \beta$ (GSK3 $\beta$ ) expression. In addition, a lower miR-101 expression is related to a worse survival prognosis of GBM patients, thus suggesting its potential role as a prognostic biomarker [158].

\subsection{8. miRNA-107}

MiRNA-107 is another miRNA which associates with NEAT. The expression of miRNA-107 is down-regulated in glioma cell lines and tissue. An elevated miR-107 expression suppressed growth, migration and invasion abilities of glioma cells, directly targeting Notch2 and inhibiting Notch2, Tenascin-C, MMP-12 and Cox-2 expression [159]. Chen et al. also showed that a high miR-107 expression inhibits glioma cell proliferation, invasion and down-regulates the expression of Notch2, stem cell markers CD133, Nestin and MMP-12 in the U87GSC cell line, thus indicating its potential therapeutic role in glioma treatment [160]. A low expression of miR-107 induces apoptosis in glioma cells possibly through the regulation of the FADD/caspase-8/caspase-3/7 signaling pathway [161]. Moreover, a low expression of miR-107 induces glioma angiogenesis through the activation of VEGF expression [162]. Furthermore, miR-107 down-regulation is significantly associated with advanced pathological grade in glioma patients, large tumor size and lower Karnofsky performance score. Those patients with a low miR-107 expression had shorter overall survival and progression-free survival rates, compared to patients with elevated miR-107 expression, thus showing its value as a prognostic biomarker in glioma [163].

\subsection{9. $\mathrm{miR}-122$}

UCA1 also down-regulates the expression of miR-122 [109]. Down-regulation of miR-122 is associated with tumor proliferation, invasion and migration via the Wnt/ $\beta$-catenin signaling pathway [129-131]. Su et al. demonstrated that miR-122 expression is down-regulated in human glioma tissues and glioblastoma stem cells [164]. The dual-luciferase reporter assay revealed that miR-122 directly targets SOX2 Overlapping Transcript (SOX2OT) gene and increases its expression. 
A low expression of SOX2OT is associated with inhibited proliferation, migration and invasion of glioblastoma stem cells [164]. Moreover, Yerukala et al. showed that miR-122 expression correlates with the survival time of patients with glioblastoma and could be used as a prediction biomarker [165].

\subsubsection{0. $\mathrm{miR}-137$}

It was shown that miR-137 directly regulates the expression of Rac1, which plays important role in cell cycle progression, growth and cell motility. Sun et al. also demonstrated that low miR-137 expression in glioma tissue, compared with healthy brain tissue, induces proliferation, inhibited cell cycle arrest and induced cell apoptosis [166]. Li et al. showed that expression of miR-137 in blood serum is down-regulated in GBM patients compared to healthy controls [167]. This down-regulation strongly correlates with glioma clinical grade, Karnofsky performance score and poor survival of GBM patients [167]. MiR-137 also inhibits cell proliferation and angiogenesis of GBM cells by directly regulating the level of Polycomb group protein EZH2 [168]. Thus, an interaction of lncRNA Xist and miR-137 can be a very promising target for the treatment of glioma.

\subsubsection{1. $\mathrm{miR}-140$}

Multiple lncRNA interactions with miR-140 also highlight the importance of this miRNA in glioma. H19, MALAT1 and HOXA11-AS down-regulates the expression of miR-140-5p in glioma. Low expression levels of miR-140 correlate with an enhanced cell proliferation, migration and invasion processes. It was shown that miR-140 directly targets disintegrin and metalloproteinase ADAM9 genes [169]. miR-140 is also involved in blood-tumor barrier permeability regulation. Ma et al. showed that nuclear transcription factor Y subunit alpha (NFYA) is another target of miR-140 and acts as a transcription factor regulating the expression of ZO-1, occludin and claudin-5 [80]. In addition, it was shown that miR-140-5p increases the expression of VEGFA and MMP2 in vitro [133].

\subsubsection{2. $\mathrm{miR}-142$}

It has been shown that the expression of tumor suppressive miR-142 is associated with inhibited cancer cell proliferation and invasiveness. LncRNAs may function as miRNA sponges, thus reducing their regulatory impact on mRNAs. Zhang et al. showed an association between IncRNA TP73-AS1 and miR-142, which controls glioma cell growth via the HMGB1/RAGE pathway [103]. Moreover, miR-142 expression is down-regulated in glioma cell lines and tumor tissue and correlates with glioma tumor grade and glioma patients' survival. Overexpression of miR-142 inhibited glioma cell migration and invasion abilities through regulating Rac1 and Integrin Subunit Beta 8 (ITGB8) expression [170,171]. Rac1 is a GTP-bound protein, involved cell migration and invasion processes and taking part in the $\mathrm{PI} 3 \mathrm{~K} / \mathrm{Akt} / \mathrm{mTOR}$ and MAPK signaling pathways [170]. ITGB8 is a member of the integrin family and is involved in tumorigenesis [170].

\subsubsection{3. $\mathrm{miR}-144$}

It was shown that TUG1 competes with miR-144. The authors showed that miR-144 can inhibit the expression of HSF2 which acts as a transcription factor for tight junction proteins. The relationship between TUG1, mir-144, and HSF2 was demonstrated in an animal model system [105]. Lan et al. demonstrated that the level of miR-144-3p was significantly down-regulated in glioma tumor tissue compared with healthy brain tissues and decreased with higher glioma grades [172]. In addition, low miR-144-3p expression was associated with worse overall survival in glioma patients. miR-144-3p inhibited GBM cell proliferation and invasion by suppressing its direct target met in vitro and in vivo [172]. A direct correlation with one important oncogene MET makes this miRNA a very promising target. 


\subsubsection{4. $\mathrm{miR}-152$}

The third known miRNA interacting with Xist is miR-152. The expression of miR-152 is lower in glioma. The invasion assay showed that miR-152 regulates cell invasiveness via binding to its direct target gene MMP-3 [173]. A low miR-152 expression enhanced cell proliferation, whereas a high miR-152 expression promoted glioma cell apoptosis by regulating the expression of Runt Related Transcription Factor 2 (Runx2) [174]. Furthermore, miR-152 directly targets DNA methyltransferase 1 (DNMT1) gene. Both miR-152 overexpression and DNMT1 knockdown are significantly associated with induced apoptosis and inhibited invasiveness [175].

\subsubsection{5. $\mathrm{miR}-155$}

On other hand, MALAT1 negatively regulates the expression of miR-155 and positively, the expression of miR-203 and miR-101. The expression of miR-155 is elevated in glioma tumor tissue when compared to the healthy tissue. Contrariwise, a decreased expression of miR-155 inhibited the proliferation of glioma cells and the activation of the Wnt/ $\beta$-catenin pathway, as well as suppressed the growth of U-87 MG glioma xenografts in mice [176]. Decreasing the level of miR-155 expression sensitizes glioma cells to the temozolomide (TMZ) by targeting the p38 isoforms MAPK13 and MAPK14 [177]. The expression of miR-155, in parallel, is regulated by lncRNA MIR155HG. Wu et al. showed that the MIR155HG/miR-155-3p/miR-155-5p axis plays a key role in glioma progression and may be used as a prognostic factor for glioblastoma patient survival [88].

\subsubsection{6. $\mathrm{miR}-181$}

Multiple interactions of various lncRNAs with miR-181 indicates the importance of this microRNA in glioma. LncRNA CCAT1 by interacting with miR-181b regulates tumorigenesis and EMT of glioma [48]. Besides, Zhou et al. showed that decreased expression of miR-181b stimulates proliferation, migration and invasion in vitro via negative regulation of SALL4 (Sal-like protein 4) expression [178]. In addition, the increased expression of miR-181b suppressed the levels of cyclin D1, c-Myc and Ki-67 proteins, essential for cell proliferation [179]. The expression of MiR-181b differs between LGG and HGG glioma tumors, thus indicating that miR-181b expression is associated with glioma malignancy [180]. Evidence shows that miR-181b may be involved in chemosensitivity for its ability to change the sensitivity to teniposide through binding MDM2 3'-UTR region [181]. Another miRNA that belongs to the miR-181 family is miR-181d. It is associated with lncRNA NEAT1 and increases BTB permeability [91]. In parallel, it was shown that Insulin-like Growth Factor (IGF-1) is a direct target of this miRNA and is relevant in regulating cell growth and cytokine secretions. High IGF-1 level and low miR-181d expression levels were related to poor patient survival, thus suggesting its role as a prognostic factor in glioblastomas [182]. MiR-181d also targets K-ras, bcl-2 [183] and down-regulates MGMT expression [184]. The elevated expression of miR-181a is associated with lncRNA CASC2 and modulates the resistance to TMZ [44]. Additionally, Ma et al. showed that up-regulation of miR-181a is also associated with increased BTB and decreased expression of ZO-1, occludin, and claudin-5. Moreover, Kruppel-Like Factor 6 (KLF-6) is a direct target of miR-181a and might play an important role in regulating BTB permeability [185].

\subsubsection{7. $\mathrm{miR}-182$}

One of UCA1 regulating miRNAs is miR-182, significantly expressed in the oligoneural subclass of GBM. It promotes the apoptotic response of glioma cells to anti-cancer agents (TMZ and RTK inhibitors) by suppressing the expression of Caspase and p53 inhibitor Bcl2L12 genes [186]. Feng et al. also demonstrated that miR-182 regulates the cell cycle and cell migration in vitro, though modifying the expression of Neuritin 1 (NRN1) gene-a novel member of the neurotrophic factors family, which has been shown to be associated with tumor malignancy [187]. In addition, Xue et al. showed that miR-182-5p induces the proliferation and invasion of glioma cells by directly targeting PCDH8 gene 
(protocadherin 8) [188]. Furthermore, study results demonstrated that levels of circulating miR-182 in glioma patients' blood were higher in comparison to healthy controls, and the expression of miR-182 is positively associated with Karnofsky performance score and tumor grade. These data suggest that miR-182/UCA1 may be used as novel biomarkers for prognosis in patients with glioma [189].

\subsubsection{8. miR-186, miR-190a-5p, miR-488-3p}

Newly identified lncRNA PVT1 is currently known to regulate the expression of 3 miRNAs: miR-186, miR-488-3p and miR-190a-5p. The expression of miR-186 in glioma tissues is significantly lower in comparison to the healthy brain tissue and negatively correlates with increasing pathological glioma grade [99,190]. It is known that miR-186 regulates Caspase3, Cyclin D1, Bcl-2-associated death promoter (BAD) and Microtubule Affinity Regulating Kinase 2 (MARK2) levels by targeting X-Linked Inhibitor of Apoptosis (XIAP) and P21 (RAC1) Activated Kinase 5 (PAK7) 3'-UTR. A low miR-186 expression was associated with enhanced proliferation, migration, invasion abilities and inhibited apoptosis in glioma stem cells [190]. In addition, this miRNA is also regulated by lncRNA CRNDE [190]. Unfortunately, there is no additional information about the other two other miRNA associated with lncRNA PVT1: miR-488-3p and miR-190a-5p.

\subsubsection{9. miR-200a}

Berthois et al. demonstrated for the first time that miR-200a expression is down-regulated in high grade glioma samples compared with low grade glioma [191]. An overexpression of miR-200a promotes sensitivity to temozolomide in GBM cells. Moreover, the DNA repair enzyme $\mathrm{O}$ (6)-methylguanine methyltransferase (MGMT) was identified as a direct target of miR-200a the suppression of which results in miR-200a expression increment [191]. Despite the evidence of interaction between lncRNA ATB and miR-200a it remains unknown, whether lncRNA ATB expression affects chemosencitivity to TMZ.

\subsubsection{0. $\mathrm{miR}-203$}

The expression of miR-203 is regulated by MALAT1 and CCDC26. Snail family transcriptional repressor 2 (SNAI2) plays an important role in epithelial to mesenchymal transition and was identified as a direct target of miR-203. Down-regulation of SNAI2 expression was associated with EMT inhibition and drug resistance. Lower miR-203 expression was associated with poorer glioblastoma clinical outcomes [192]. Pal et al. showed that miR-203 can regulate cell proliferation and migration in human glioblastoma cells through GAS41/miR-10b axis [193]. On the other hand, it was shown that miR-203 targets Ataxia Telangiectasia Mutated (ATM) and the inhibition of ATM expression sensitizes the cells to various chemotherapeutic agents [194]. All this data makes MALAT and CCDC26 important targets.

\subsubsection{1. $\mathrm{miR}-326$}

Recently, miR-326 was shown to play an important role in glioma progression. Zhou et al. identified NIN1 (RPN12) binding protein 1 homolog (NOB1) as a direct target of miR-326, and it is a potential oncogene in human glioma. A high miR-326 expression in A172 and U373 human glioma cell lines caused cell cycle arrest, suppressed cell proliferation and enhanced apoptosis. Moreover, miR-326 may inhibit cell colony formation and reduce growth of a xenograft tumor, thus indicating that miR-326 and NOB1 are important for glioma progression both in vitro and in vivo [195]. Another miR-326 target is the SMOothened (SMO) gene. A high miR-326 expression suppresses the expression of SMO and other down-stream genes, and, in turn, inhibits activity of the Hedgehog pathway in U251 tumor stem cells [196]. It was confirmed that HOTAIR IncRNA directly binds miR-326. As FGF1, which plays an important role in glioma by activating PI3K/AKT and MEK $1 / 2$ pathways is a target of miR-326, an increased expression of miR-326 reduced FGF1 expression level [69]. Thus, HOTAIR/miR-326/FGF1 plays an important role in glioma. 


\subsubsection{2. $\mathrm{miR}-342-3 \mathrm{p}$}

One of such miRNA is miR-342-3p associated with lncRNA FTX [59]. MiR-342-3p regulates the expression of Astrocyte-elevated gene-1 (AEG1). AEG-1 is an important player in the carcinogenic process, in diverse organs and tissues, and it can act through multiple pathways, including PI3K/Akt, NF- $\mathrm{kB}$, Wnt/ $\beta$-catenin and MAPK $[126,197]$. In addition, it was shown that miR-342-3p expression was remarkably lower in the GBM group, compared to healthy controls, and could help to separate glioma from healthy controls with high specificity and sensitivity. Also, there were significant differences in miR-342-3p expression levels between glioma patients with grade II, III and IV. Plasma levels of miR-342-3p were particularly decreased in glioma with higher tumor grades [198]. Similar results showed Roth et al. comparing miRNA profiles from the blood in glioblastoma patients and healthy controls [127]. It was determined that miR-342-3p expression was significantly lower in the glioblastoma patient group [127]. It makes lncRNA FTX a very promising target for novel treatment of glioma. However, there is no data about miR-342p expression in glioma tissue [127].

\subsubsection{3. $\mathrm{miR}-384$}

Another miRNA which may be associated with glioma progression and lncRNA CRNDE is miR-384. The expression of miR-384 is significantly down-regulated in glioma tissue and glioma cell lines compared to healthy brain tissue and normal human astrocytes. The expression of miR-384 also negatively correlates with glioma progression grade. A high miR-384 expression is associated with inhibited proliferation in U87 and U251 cell lines. It has been shown that miR-384 targets PIWIL4 $3^{\prime}$-UTR and suppresses glioma cell malignancy via regulating the expression of cyclin D1,VEGFA, SNAI2, MMP-9, Bcl-2, Bcl- $x$ L and Caspase 3 genes [53].

\subsubsection{4. $\mathrm{miR}-429$}

MiR-429, which is a target of Xist, is able to activate endothelial monocyte activating polypeptide-II (EMAP-II). EMAP-II regulates BTB permeability by changing ZO-1, Occludin and Claudin-5 expression [199]. However, the role of Xist in BTB via miR-429 was not proved yet. SOX2 is another target of miR-429 [200], and the role of lncRNA in this pathway not revealed yet.

\subsubsection{5. miR-449b-5p}

Little is known about the role of miR-449b-5p in glioma. There is only one study showing a negative correlation between miR-449b-5p and lncRNA NEAT expression. Besides, the results revealed that miR-449b-5p directly targets the met gene [94].

Increasing numbers of studies have revealed the presence of an interaction network, where ncRNAs could regulate mRNA by binding to its $3^{\prime}$-UTR, thus modifying protein expression [201]. This evidence suggests that lncRNAs are associated with ncRNAs, such as miRNAs, and may play an important role in glioma pathogenesis [202]. The possibility of a single miRNA affecting the expression of hundreds mRNA can help us identify new biological pathways in glioma. The biological role of miRNA in the glioma treatment and tumorigenesis is still in question. Dysregulation of miRNAs expression profiles may be associated with glioma progression by the modulation of cell proliferation, invasion and apoptosis [203]. Therefore, miRNAs may have a clinical potential for a targeted therapy or glioma molecular diagnosis and prognosis [204].

\subsection{The Potential of Non-Coding RNAs for the Prediction of Resistance to Chemotherapy}

Development of drug resistance is the major problem is that observed in glioma treatment. Changes in ncRNA expression are associated with response to treatment and may have value as prognostic and predictive biomarkers. Attempts to identify the lnc-RNAs, associated with chemoresistance, is very important for TMZ-resistant glioma. A few observations support the potential of non-coding RNAs as predictors of sensitivity to TMZ treatment. 


\subsubsection{H19 lncRNA}

It was shown that TMZ resistant patients had higher levels of lncRNA H19. This effect is mediated via major drug resistance genes, such as Multidrug-resistant $(M D R)$, Multidrug resistance-associated protein $(M R P)$, and ATP Binding Cassette Subfamily G Member 2 (ABCG2), the expression of which was altered in both mRNA and protein level [63]. Jia et al. showed that H19 increases chemoresistance by activating EMT via the Wnt/ $\beta$-catenin pathway [205].

\subsubsection{Xist lncRNA, miR-29c}

LncRNA Xist is potentially associated with resistance to chemotherapy. Xist is up-regulated in $33.33 \%$ of glioblastoma cases and correlates with a glioma grade, tumor size, and survival prognosis. Elevation of Xist expression down-regulates miR-29c, which is also responsible for the chemosensitivity in breast cancer [154,206-208]. In addition, it was shown that Xist/miR-29c regulates chemosensitivity via transcription factor gene SP1 and O-6-Methylguanine-DNA Methyltransferase (MGMT) gene expression [116].

\subsection{3. $\mathrm{miR}-181 \mathrm{a}, \mathrm{miR}-193 \mathrm{a}-5 \mathrm{p}$}

Jiang et al. showed that a decreased expression of CASC-2 in glioma is associated with a TMZ-induced autophagy. The study showed that TMZ resistance is determined by miR-193a-5p via the mTOR signaling pathway and inhibition of autophagy restored chemosensitivity [46]. CASC2 also induces chemoresistance by down-regulating the miR-181a/PTEN pathway [44].

\subsubsection{MALAT1 lncRNA, miR-203}

LncRNA MALAT1 is also observed to influence chemoresistance. It induces TMZ resistance by down-regulating miR-203 which, in turn, increases the expression of thymidylate synthase (TS). TS is a key regulator of cell proliferation, and lncRNA MALAT 1 is able to suppress cell proliferation through miR-203-TS pathway in TMZ resistant cell lines [85].

Overall, observed effects to the sensitivity to chemotherapy of glioma cells, suggest the consideration of these specific miRNAs and lncRNAs as potential biomarkers for the therapeutic approach that may lead to a longer progression free and overall survival of glioma patients.

\subsection{Non-Coding RNAs in Angiogenesis}

The major hallmark of cancer is tumor vascularization or sustained angiogenesis [209]. Malignant gliomas are characterized as the most vascular of all solid tumors, therefore angiogenesis is considered to be the main feature of glioma progression. Although the hypoxia is a well-known driver for vascularization, there is also evidence that non-hypoxia driven mechanisms exist [210-212]. Moving further, Hardee and Zagzag indicated at least five mechanisms of neovascularization in glioblastomas [213]. The major player of vascularization is growth factor VEGF under reduced oxygen conditions. The hypoxic response in glioblastoma cells is characterized by high levels of hypoxia-inducible factor (HIF-1 $\alpha$ ) and VEGF $[34,210,214]$. Transcription factor HIF-1 $\alpha$ regulates $\sim 60$ genes involved in cell pathways such as anaerobic glycolysis, metabolism, angiogenesis, invasion, and EMT [215]. However, in normoxia, glioma cell angiogenesis is activated through the PI3K/Akt/mTOR pathway. Activation of serine/arginine-rich splicing factor kinase 1 (SRPK1) expression which regulates phosphorylation of Akt and controls of VEGF splicing, induces the PI3K/Akt pathway and angiogenesis in glioma under normoxic conditions [216].

\subsubsection{H19 lncRNA, miR-29a, miR-675-5p}

Currently, a few studies revealed the association between non-coding RNA and angiogenesis. Jia et al. showed, that the expression of lnc-RNA H19 is up-regulated in glioma microvessels compared to normal brain microvessels [65]. The suppressed expression of H19 inhibits tube formation through 
Vasohibin 2 (VASH2), one of the angiogenesis factors. VASH2 is independent of VEGF and is a new potential target for tumor therapy [217-219]. It was shown that H19 also inhibits miR-29a that, in turn, negatively regulates VASH2 expression [65]. The effect of $\mathrm{H} 19$ on angiogenesis was also proved by Jiang et al. in vitro and in vivo [64]. In parallel, it was shown that miR-675-5p, generated from H19, is involved in angiogenesis induced by hypoxia [220].

\subsubsection{HULC, POU3F3 lncRNAs}

Lang et al. showed that elevated expression of IncRNA-POU3F3 induces angiogenesis through $b F G F, V E G F A, b F G F R$, and Angio genes. LncRNA-POU3F3 can be packed into an exosome and transferred to an endothelial cell where it can induce a formation of new blood vessels [96,221]. Elevation of LncRNA HULC expression induces the expression of Endothelial Cell Specific Molecule 1 (ESM-1) gene. ESM-1 is known as a molecular signature of angiogenesis. Its expression is activated by the VEGF/PI3K pathway [77].

\subsubsection{Xist lncRNA, miR-137, miR-429}

LncRNA Xist was observed to affect angiogenesis. It was shown that reduced expression of Xist reduced angiogenesis in vivo by directly regulating the expression of miR-429 [115]. In parallel, Xist is able to induce angiogenesis via miR-137, which targets tight junction protein gene ZO-2 and Forkhead Box $\mathrm{C} 1$ (FOXC1), and FOXC1 is able to promote atypical chemokine receptor 3 (ACKR3) expression and activate angiogenesis [113].

\subsubsection{HOTAIR IncRNA}

A suppressed expression of lncRNA HOTAIR inhibits pro-angiogenetic activities of the glioma cells. It was shown that lncRNA HOTAIR mediates angiogenesis via VEGFA [71]

\subsubsection{PVT1, SNHG15 lncRNAs, miR-153, miR-186}

An increased expression of lncRNA SNHG15 activates angiogenesis via miR-153, which, in turn, activates the expression of VEGFA and CDC42 genes [222]. High levels of lncRNA PVT1 induce angiogenesis and tube formation by down-regulating miR-186 [99].

Taken together, these studies demonstrate the relationship between an altered lncRNAs expression and the glioma tumor angiogenesis mechanisms. All these lncRNAs are potential targets for the anti-angiogenesis therapies. Further investigations are needed to widen the knowledge in this field.

\subsection{Non-Coding RNAs and Regulation of Blood-Tumor-Barrier}

The blood-tumor barrier (BTB) is one of the factors that influence the efficiency of glioma treatment. This process depends on tight junction proteins, such as cloudin and occludin, and their interaction with multiprotein complex, consisting of cytoplasmic scaffolding ZO proteins [223,224].

Ma et al. showed that suppressed expression of lncRNA MALAT1 increased BTB permeability and decreased the expression of tight junction proteins [80]. Further, it was shown that MALAT1 is a target of miR-140, also regulating BTB permeability and the expression of tight junction proteins. There is a negative correlation between MALAT1 and miR-140. Ma et al. showed that another miR-140 target is the NFYA gene that acts as a transcription factor and regulates expression of ZO-1, occludin and claudin-5 [80]. Low expression of the lncRNA NEAT1 is associated with miR-181d-5p increment, which in turn regulates BTB permeability and the expression of ZO-1, occludin, and claudin-5 through SOX5 [91]. Down-regulation of lncRNA TUG1 expression increased BTB permeability and reduced the expression of ZO-1, occludin and claudin-5. It was shown that lncRNA TUG1 competes with miR-144 for the regulation of tight junction protein expression. Authors showed that miR-144 can inhibit Heat Shock Transcription Factor 2 (HSF2) expression. HSF2 acts as a transcription factor for tight junction proteins. The relationship between lncRNA TUG1, mir-144, and HSF2 was also demonstrated in an animal 
model system [105]. Decreasing the expression of lncRNAs HOTAIR and Xist leads to an increased BTB permeability and a decreased expression of tight junction proteins $\mathrm{ZO}-1, \mathrm{ZO}-2$ and occludin, together with an increasing expression of miR-148b-3p and miR-137 respectively $[67,113]$. An up-regulated expression of lncRNA MEG3 increases BTB permeability via the PIWI1/MEG3/mir-330/RUNX3 axis [225].

These results demonstrate that miRNAs and lncRNAs should be investigated more widely, since it might serve as potential targets in regulating the BTB and providing a new strategy for the glioma treatment.

\section{Discussion}

Glioma still remains one of the diseases with worst outcome, despite the progress in diagnostics and treatment. Molecular biomarkers play an essential role in diagnostics and individualized treatment of the patients. According to the new World Health Organization (WHO) classification of gliomas, the application of protein and/or nuclear acid based molecular tests are necessary for integrated diagnosis of gliomas. These routine laboratory tests involve the identification of isocitrate dehydrogenase (IDH1/2) mutation, 1p/19q co-deletion, H3 Histone Family Member 3A (H3F3A) mutation, gene for Histone (H3HIST1H3B/C) mutation, RELA fusion, Telomerase Reverse Transcriptase (TERT) promoter mutation, KIAA1549/BRAF fusion and BRAF-V600E mutation [226,227]. However, evidence shows that these mutations also could be regulated by miRNAs. Cheng et al showed that in total 361 of 487 miRNAs were differentially expressed, depending on the IDH1/2 mutation. Four miRNAs (miR-10b, miR-130b, miR-1304 and miR-302b) were highlighted as a marker for a high or low-risk of poor prognosis associated with the IDH1/2 mutations in lower-grade glioma patients [228].

Microarray data analysis revealed that the expression of 13 lncRNAs is associated with the IDH1 mutation status. KIAA0495 and HOTAIRM1 were the most down-regulated, and LOC254559 together with LINC00689 were most up-regulated lncRNAs [229]. However, there is still no data about the roles of these RNAs in glioma formation. Furthermore, Jha et al. showed that H3F3A mutation is associated with up-regulation of miR-17/92 and its paralog clusters (miR106b/25 and miR-106a/363) and down-regulation of miRNAs belonging to miR379/656 cluster in pediatric high-grade gliomas. In total, 97 miRNAs (62 up- and 35 down-regulated) and 74 miRNAs (21 up- and 53 down-regulated) were found to be $H 3 F 3 A$ mutation and wild-type specific, respectively. The expression of four miRNAs (miR-15a, miR-424, miR-30e, and miR-378c) was higher in samples with H3F3A mutation, when compared to wild type [230]. These findings suggest that miRNAs can be used as specific biomarkers for identification of specific mutations and play an important role in mutation specific gene profiles. Further associations of these miRNAs with treatment outcomes would facilitate the development of novel tools for treatment individualization.

In addition, other less investigated non-coding RNA species, including small nucleolar RNAs (snoRNAs, scaRNA), piwi RNAs (piRNAs) and circular RNAs (circRNAs), have a potential for application as future biomarkers of glioma. Small nucleolar RNAs (snoRNAs) play roles in many biological functions, including biochemical modifications of other RNAs, precursors of miRNA, splicing, and telomerase activity [231]. The genome wide analysis of snoRNA in pediatric gliomas revealed that there were 118 differentially up-regulated (three scaRNAs, 17 snoRNAs, 26 HACA-Box and 72 CD-Box) and 39 down-regulated (38 CD-Box and one snoRNA) small-noncoding RNAs [230]. It was shown that snoRNA SNORD regulates EMT and sensitivity to temozolomide [232]. C/D box snoRNA U76 (SNORD76) inversely associates with an expression of HOTAIR and affects cell proliferation in vitro and in vivo. The elevated expression of SNORD76 reduces the expression of cyclin $A 1$, cyclin $B 1$ and $p 107$ genes and an increase the expression of $R b$ gene [233]. Up-regulation of snoRNA SNHG18 increases glioma cell radioresistance by repressing Semaphorin 5A [234]. Currently, there is no data about SNHG18 expression pattern in glioma tissue. Recently, the overexpression of snoRNA SNHG1 in glioma tissue was determined, and it correlated with increased tumor cell proliferation and reduced apoptosis; however, the exact cellular pathway and biological targets remain 
to be discovered [235]. The biological function of scaRNA in glioma is still unknown, but there are several reports where their expression varied in other types of cancer [236,237]. The circular RNA is another group of non-coding RNA serving as a miRNA sponges and sharing the same binding sites $[238,239]$. Recently, some circRNAs were identified as significant players in glioma development. It was shown that circ-TTBK2 is up-regulated in glioma and cell lines, such as U87 and U251. The down-regulation of circ-TTBK2 together with the overexpressed miR-217 inhibited tumor growth in mice [240]. Furthermore, the expression of circ-FBXW7 is down-regulated in glioma compared to normal brain tissue and higher cicr-FBXW7 expression levels are associated with a better overall survival of glioma patients [241]. Circular RNA CircZNF292 is involved angiogenesis, besides, it's overexpression in U87MG and U251 glioma cell lines and activates cell proliferation processes via the Wnt/ $\beta$-catenin signaling pathway. Unfortunately, there is no data about circZNF292 expression in glioma tissue yet [242]. piRNAs, another type of small non-coding RNAs, is generated from precursor RNA which differs from miRNA precursors [243]. piRNA regulates gene expression by triggering epigenetic modification [244] and induces mRNA degradation [245]. PIWI/piRNA complexes regulate cell proliferation, differentiation and cell death [246-248]. In addition, piRNA can interact with miRNA and siRNA and modulate cellular processes $[249,250]$. BTB regulation via the PIWI1/MEG3/miR-330/RUNX3 axis illustrates the complexity and importance of all ncRNA in biological processes [225].

\section{Conclusions}

Brain tumors, especially glioblastoma, still remain one of the most lethal tumors despite of the modern and improved surgical and radiotherapy treatment. More efficient treatment options have to be developed in the future. Non-coding RNA could be the promising tool for targeted therapy combined with other new promising therapies. The use of a complete network of all non-coding RNAs involved in glioma formation and progression could supplement other therapeutic opportunities such as immunotherapy and gene therapy and could also evolve as stratification tool for treatment individualization resulting in a better antitumor benefit.

Author Contributions: Writing-Original Draft Preparation, R.R., J.S.; Writing—Review and Editing, E.S., V.S., J.U., E.M.K., I.M., J.C.; Visualization, R.R., V.S.; Supervision, K.S.; Project Administration, J.U.; Funding Acquisition, J.U., K.S.

Funding: This work was funded by the Research Council of Lithuania, project MIP-015/2014.

Acknowledgments: Authors are grateful to Sonata Juskeviciene and Tomas Paulauskas for the help with editing of English language.

Conflicts of Interest: The authors declare no conflict of interest.

\section{References}

1. Alfonso, J.C.L.; Talkenberger, K.; Seifert, M.; Klink, B.; Hawkins-Daarud, A.; Swanson, K.R.; Hatzikirou, H.; Deutsch, A. The biology and mathematical modelling of glioma invasion: A review. J. R. Soc. Interface 2017, 14. [CrossRef] [PubMed]

2. Xu, W.; Li, T.; Gao, L.; Zheng, J.; Shao, A.; Zhang, J. Efficacy and safety of long-term therapy for high-grade glioma with temozolomide: A meta-analysis. Oncotarget 2017, 8, 51758-51765. [CrossRef] [PubMed]

3. Li, G.; Qin, Z.; Chen, Z.; Xie, L.; Wang, R.; Zhao, H. Tumor Microenvironment in Treatment of Glioma. Open Med. 2017, 12, 247-251. [CrossRef] [PubMed]

4. Louis, D.N.; Perry, A.; Reifenberger, G.; von Deimling, A.; Figarella-Branger, D.; Cavenee, W.K.; Ohgaki, H.; Wiestler, O.D.; Kleihues, P.; Ellison, D.W. The 2016 World Health Organization Classification of Tumors of the Central Nervous System: A summary. Acta Neuropathol. 2016, 131, 803-820. [CrossRef] [PubMed]

5. Crocetti, E.; Trama, A.; Stiller, C.; Caldarella, A.; Soffietti, R.; Jaal, J.; Weber, D.C.; Ricardi, U.; Slowinski, J.; Brandes, A. Epidemiology of glial and non-glial brain tumours in Europe. Eur. J. Cancer 2012, 48, 1532-1542. [CrossRef] [PubMed] 
6. Buckner, J.C.; Shaw, E.G.; Pugh, S.L.; Chakravarti, A.; Gilbert, M.R.; Barger, G.R.; Coons, S.; Ricci, P.; Bullard, D.; Brown, P.D.; et al. Radiation plus Procarbazine, CCNU, and Vincristine in Low-Grade Glioma. N. Engl. J. Med. 2016, 374, 1344-1355. [CrossRef] [PubMed]

7. van den Bent, M.J.; Baumert, B.; Erridge, S.C.; Vogelbaum, M.A.; Nowak, A.K.; Sanson, M.; Brandes, A.A.; Clement, P.M.; Baurain, J.F.; Mason, W.P.; et al. Interim results from the CATNON trial (EORTC study 26053-22054) of treatment with concurrent and adjuvant temozolomide for $1 \mathrm{p} / 19 \mathrm{q}$ non-co-deleted anaplastic glioma: A phase 3, randomised, open-label intergroup study. Lancet 2017, 390, 1645-1653. [CrossRef]

8. Jaeckle, K.; Vogelbaum, M.; Ballman, K.; Anderson, S.K.; Giannini, C.; Aldape, K.; Cerhan, J.; Wefel, J.S.; Nordstrom, D.; Jenkins, R.; et al. CODEL (Alliance-N0577; EORTC-26081/22086; NRG-1071; NCIC-CEC-2): Phase III Randomized Study of RT vs. RT+TMZ vs. TMZ for Newly Diagnosed 1p/19q-Codeleted Anaplastic Oligodendroglial Tumors. Analysis of Patients Treated on the Original Protocol Design (PL02.005). Neurology 2016, 86, PL02-005.

9. De Sanctis, V.; Mazzarella, G.; Osti, M.F.; Valeriani, M.; Alfo, M.; Salvati, M.; Banelli, E.; Tombolini, V.; Enrici, R.M. Radiotherapy and sequential temozolomide compared with radiotherapy with concomitant and sequential temozolomide in the treatment of newly diagnosed glioblastoma multiforme. Anti-Cancer Drugs 2006, 17, 969-975. [CrossRef]

10. Stupp, R.; Taillibert, S.; Kanner, A.; Read, W.; Steinberg, D.; Lhermitte, B.; Toms, S.; Idbaih, A.; Ahluwalia, M.S.; Fink, K.; et al. Effect of Tumor-Treating Fields Plus Maintenance Temozolomide vs Maintenance Temozolomide Alone on Survival in Patients With Glioblastoma: A Randomized Clinical Trial. JAMA 2017, 318, 2306-2316. [CrossRef]

11. Bracken, C.P.; Scott, H.S.; Goodall, G.J. A network-biology perspective of microRNA function and dysfunction in cancer. Nat. Rev. Genet. 2016, 17, 719-732. [CrossRef] [PubMed]

12. Lander, E.S.; Linton, L.M.; Birren, B.; Nusbaum, C.; Zody, M.C.; Baldwin, J.; Devon, K.; Dewar, K.; Doyle, M.; FitzHugh, W.; et al. Initial sequencing and analysis of the human genome. Nature 2001, 409, 860-921. [CrossRef] [PubMed]

13. Stahlhut, C.; Slack, F.J. MicroRNAs and the cancer phenotype: Profiling, signatures and clinical implications. Genome Med. 2013, 5, 111. [CrossRef] [PubMed]

14. Bolha, L.; Ravnik-Glavac, M.; Glavac, D. Long Noncoding RNAs as Biomarkers in Cancer. Dis. Mark. 2017, 2017, 7243968. [CrossRef] [PubMed]

15. Quinn, J.J.; Chang, H.Y. Unique features of long non-coding RNA biogenesis and function. Nat. Rev. Genet. 2016, 17, 47-62. [CrossRef] [PubMed]

16. Wilusz, J.E.; Sunwoo, H.; Spector, D.L. Long noncoding RNAs: Functional surprises from the RNA world. Genes Dev. 2009, 23, 1494-1504. [CrossRef] [PubMed]

17. Fejes-Toth, K.; Sotirova, V.; Sachidanandam, R.; Assaf, G.; Hannon, G.J.; Kapranov, P.; Foissac, S.; Willingham, A.T.; Duttagupta, R.; Dumais, E.; et al. Post-transcriptional processing generates a diversity of 5'-modified long and short RNAs. Nature 2009, 457, 1028-1032. [CrossRef]

18. Tam, O.H.; Aravin, A.A.; Stein, P.; Girard, A.; Murchison, E.P.; Cheloufi, S.; Hodges, E.; Anger, M.; Sachidanandam, R.; Schultz, R.M.; et al. Pseudogene-derived small interfering RNAs regulate gene expression in mouse oocytes. Nature 2008, 453, 534-538. [CrossRef]

19. Yoon, J.H.; Abdelmohsen, K.; Gorospe, M. Functional interactions among microRNAs and long noncoding RNAs. Semin. Cell Dev. Biol. 2014, 34, 9-14. [CrossRef]

20. Yu, Y.; Nangia-Makker, P.; Farhana, L.; Majumdar, A.P.N. A novel mechanism of lncRNA and miRNA interaction: CCAT2 regulates miR-145 expression by suppressing its maturation process in colon cancer cells. Mol. Cancer 2017, 16, 155. [CrossRef]

21. Bayoumi, A.S.; Sayed, A.; Broskova, Z.; Teoh, J.P.; Wilson, J.; Su, H.; Tang, Y.L.; Kim, I.M. Crosstalk between Long Noncoding RNAs and MicroRNAs in Health and Disease. Int. J. Mol. Sci. 2016, 17, 356. [CrossRef] [PubMed]

22. Homami, A.; Ghazi, F. MicroRNAs as biomarkers associated with bladder cancer. Med. J. Islam. Repub. Iran 2016, 30, 475. [PubMed]

23. Misawa, A.; Takayama, K.I.; Inoue, S. Long non-coding RNAs and prostate cancer. Cancer Sci. 2017. [CrossRef] [PubMed]

24. Shen, L.; Liu, W.; Cui, J.; Li, J.; Li, C. Analysis of long non-coding RNA expression profiles in ovarian cancer. Oncol. Lett. 2017, 14, 1526-1530. [CrossRef] [PubMed] 
25. Sun, Y.; Zou, X.; He, J.; Mao, Y. Identification of long non-coding RNAs biomarkers associated with progression of endometrial carcinoma and patient outcomes. Oncotarget 2017, 8, 52604-52613. [CrossRef] [PubMed]

26. Switlik, W.Z.; Szemraj, J. Circulating miRNAs as non-invasive biomarkers for non-small cell lung cancer diagnosis, prognosis and prediction of treatment response. Postepy Higieny i Medycyny Doswiadczalnej (Online) 2017, 71, 649-662. [CrossRef] [PubMed]

27. Waseem, M.; Ahmad, M.K.; Srivatava, V.K.; Rastogi, N.; Serajuddin, M.; Kumar, S.; Mishra, D.P.; Sankhwar, S.N.; Mahdi, A.A. Evaluation of miR-711 as Novel Biomarker in Prostate Cancer Progression. Asian Pac. J. Cancer Prev. APJCP 2017, 18, 2185-2191. [CrossRef] [PubMed]

28. Zhao, H.; Shen, J.; Hodges, T.R.; Song, R.; Fuller, G.N.; Heimberger, A.B. Serum microRNA profiling in patients with glioblastoma: A survival analysis. Mol. Cancer 2017, 16, 59. [CrossRef]

29. Zhu, H.; Chen, X.; Hu, Y.; Shi, Z.; Zhou, Q.; Zheng, J.; Wang, Y. Long non-coding RNA expression profile in cervical cancer tissues. Oncol. Lett. 2017, 14, 1379-1386. [CrossRef]

30. Inamura, K. Major Tumor Suppressor and Oncogenic Non-Coding RNAs: Clinical Relevance in Lung Cancer. Cells 2017, 6, 12. [CrossRef]

31. Chen, Y.; Zhou, J. LncRNAs: Macromolecules with big roles in neurobiology and neurological diseases. Metab. Brain Dis. 2017, 32, 281-291. [CrossRef] [PubMed]

32. Jiang, W.G.; Sanders, A.J.; Katoh, M.; Ungefroren, H.; Gieseler, F.; Prince, M.; Thompson, S.K.; Zollo, M.; Spano, D.; Dhawan, P.; et al. Tissue invasion and metastasis: Molecular, biological and clinical perspectives. Semin. Cancer Biol. 2015, 35, S244-S275. [CrossRef] [PubMed]

33. Cooper, L.A.; Gutman, D.A.; Chisolm, C.; Appin, C.; Kong, J.; Rong, Y.; Kurc, T.; Van Meir, E.G.; Saltz, J.H.; Moreno, C.S.; et al. The tumor microenvironment strongly impacts master transcriptional regulators and gene expression class of glioblastoma. Am. J. Pathol. 2012, 180, 2108-2119. [CrossRef] [PubMed]

34. Iwadate, Y. Epithelial-mesenchymal transition in glioblastoma progression. Oncol. Lett. 2016, 11, 1615-1620. [CrossRef] [PubMed]

35. Pareja, F.; Macleod, D.; Shu, C.; Crary, J.F.; Canoll, P.D.; Ross, A.H.; Siegelin, M.D. PI3K and Bcl-2 inhibition primes glioblastoma cells to apoptosis through downregulation of Mcl-1 and Phospho-BAD. Mol. Cancer Res. MCR 2014, 12, 987-1001. [CrossRef] [PubMed]

36. Foster, D.A.; Yellen, P.; Xu, L.; Saqcena, M. Regulation of G1 Cell Cycle Progression: Distinguishing the Restriction Point from a Nutrient-Sensing Cell Growth Checkpoint(s). Genes Cancer 2010, 1, 1124-1131. [CrossRef]

37. Hao, N.B.; He, Y.F.; Li, X.Q.; Wang, K.; Wang, R.L. The role of miRNA and lncRNA in gastric cancer. Oncotarget 2017, 8, 81572-81582. [CrossRef] [PubMed]

38. Li, J.; Wang, Y.M.; Song, Y.L. Knockdown of long noncoding RNA AB073614 inhibits glioma cell proliferation and migration via affecting epithelial-mesenchymal transition. Eur. Rev. Med. Pharmacol. Sci. 2016, 20, 3997-4002.

39. Wang, Y.; Kuang, H.; Xue, J.; Liao, L.; Yin, F.; Zhou, X. LncRNA AB073614 regulates proliferation and metastasis of colorectal cancer cells via the PI3K/AKT signaling pathway. Biomed. Pharmacother. 2017, 93, 1230-1237. [CrossRef]

40. Hu, L.; Lv, Q.L.; Chen, S.H.; Sun, B.; Qu, Q.; Cheng, L.; Guo, Y.; Zhou, H.H.; Fan, L. Up-Regulation of Long Non-Coding RNA AB073614 Predicts a Poor Prognosis in Patients with Glioma. Int. J. Environ. Res. Public Health 2016, 13, 433. [CrossRef]

41. Yao, J.; Zhou, B.; Zhang, J.; Geng, P.; Liu, K.; Zhu, Y.; Zhu, W. A new tumor suppressor LncRNA ADAMTS9-AS2 is regulated by DNMT1 and inhibits migration of glioma cells. Tumour Biol. J. Int. Soc. Oncodev. Biol. Med. 2014, 35, 7935-7944. [CrossRef] [PubMed]

42. Ma, C.C.; Xiong, Z.; Zhu, G.N.; Wang, C.; Zong, G.; Wang, H.L.; Bian, E.B.; Zhao, B. Long non-coding RNA ATB promotes glioma malignancy by negatively regulating miR-200a. J. Exp. Clin. Cancer Res. CR 2016, 35, 90. [CrossRef] [PubMed]

43. Wang, P.; Liu, Y.H.; Yao, Y.L.; Li, Z.; Li, Z.Q.; Ma, J.; Xue, Y.X. Long non-coding RNA CASC2 suppresses malignancy in human gliomas by miR-21. Cell. Signal. 2015, 27, 275-282. [CrossRef] [PubMed]

44. Liao, Y.; Shen, L.; Zhao, H.; Liu, Q.; Fu, J.; Guo, Y.; Peng, R.; Cheng, L. LncRNA CASC2 Interacts With miR-181a to Modulate Glioma Growth and Resistance to TMZ Through PTEN Pathway. J. Cell. Biochem. 2017, 118, 1889-1899. [CrossRef] [PubMed] 
45. Wang, R.; Li, Y.; Zhu, G.; Tian, B.; Zeng, W.; Yang, Y.; Li, Z. Long noncoding RNA CASC2 predicts the prognosis of glioma patients and functions as a suppressor for gliomas by suppressing Wnt/beta-catenin signaling pathway. Neuropsychiatr. Dis. Treat. 2017, 13, 1805-1813. [CrossRef] [PubMed]

46. Jiang, C.; Shen, F.; Du, J.; Fang, X.; Li, X.; Su, J.; Wang, X.; Huang, X.; Liu, Z. Upregulation of CASC2 sensitized glioma to temozolomide cytotoxicity through autophagy inhibition by sponging miR-193a-5p and regulating mTOR expression. Biomed. Pharmacother. 2018, 97, 844-850. [CrossRef] [PubMed]

47. Wang, Z.H.; Guo, X.Q.; Zhang, Q.S.; Zhang, J.L.; Duan, Y.L.; Li, G.F.; Zheng, D.L. Long non-coding RNA CCAT1 promotes glioma cell proliferation via inhibiting microRNA-410. Biochem. Biophys. Res. Commun. 2016, 480, 715-720. [CrossRef]

48. Cui, B.; Li, B.; Liu, Q.; Cui, Y. IncRNA CCAT1 Promotes Glioma Tumorigenesis by Sponging miR-181b. J. Cell. Biochem. 2017, 118, 4548-4557. [CrossRef]

49. Guo, H.; Hu, G.; Yang, Q.; Zhang, P.; Kuang, W.; Zhu, X.; Wu, L. Knockdown of long non-coding RNA CCAT2 suppressed proliferation and migration of glioma cells. Oncotarget 2016, 7, 81806-81814. [CrossRef]

50. Wang, S.; Hui, Y.; Li, X.; Jia, Q. Silencing of lncRNA-CCDC26 Restrains the Growth and Migration of Glioma Cells In Vitro and In Vivo Via Targeting miR-203. Oncol. Res. 2017. [CrossRef]

51. Zhang, H.; Wei, D.L.; Wan, L.; Yan, S.F.; Sun, Y.H. Highly expressed lncRNA CCND2-AS1 promotes glioma cell proliferation through Wnt/beta-catenin signaling. Biochem. Biophys. Res. Commun. 2017, 482, 1219-1225. [CrossRef] [PubMed]

52. Jing, S.Y.; Lu, Y.Y.; Yang, J.K.; Deng, W.Y.; Zhou, Q.; Jiao, B.H. Expression of long non-coding RNA CRNDE in glioma and its correlation with tumor progression and patient survival. Eur. Rev. Med. Pharmacol. Sci. 2016, 20, 3992-3996. [PubMed]

53. Zheng, J.; Liu, X.; Wang, P.; Xue, Y.; Ma, J.; Qu, C.; Liu, Y. CRNDE Promotes Malignant Progression of Glioma by Attenuating miR-384/PIWIL4/STAT3 Axis. Mol. Ther. J. Am. Soc. Gene Ther. 2016, 24, 1199-1215. [CrossRef] [PubMed]

54. Wang, Y.; Wang, Y.; Li, J.; Zhang, Y.; Yin, H.; Han, B. CRNDE, a long-noncoding RNA, promotes glioma cell growth and invasion through mTOR signaling. Cancer Lett. 2015, 367, 122-128. [CrossRef] [PubMed]

55. Kiang, K.M.; Zhang, X.Q.; Zhang, G.P.; Li, N.; Cheng, S.Y.; Poon, M.W.; Pu, J.K.; Lui, W.M.; Leung, G.K. CRNDE Expression Positively Correlates with EGFR Activation and Modulates Glioma Cell Growth. Targeted Oncol. 2017, 12, 353-363. [CrossRef] [PubMed]

56. Deguchi, S.; Katsushima, K.; Hatanaka, A.; Shinjo, K.; Ohka, F.; Wakabayashi, T.; Zong, H.; Natsume, A.; Kondo, Y. Oncogenic effects of evolutionarily conserved noncoding RNA ECONEXIN on gliomagenesis. Oncogene 2017, 36, 4629-4640. [CrossRef] [PubMed]

57. Ding, F.; Tang, H.; Nie, D.; Xia, L. Long non-coding RNA Fer-1-like family member 4 is overexpressed in human glioblastoma and regulates the tumorigenicity of glioma cells. Oncol. Lett. 2017, 14, 2379-2384. [CrossRef]

58. Chen, Z.H.; Hu, H.K.; Zhang, C.R.; Lu, C.Y.; Bao, Y.; Cai, Z.; Zou, Y.X.; Hu, G.H.; Jiang, L. Down-regulation of long non-coding RNA FOXD3 antisense RNA 1 (FOXD3-AS1) inhibits cell proliferation, migration, and invasion in malignant glioma cells. Am. J. Transl. Res. 2016, 8, 4106-4119.

59. Zhang, W.; Bi, Y.; Li, J.; Peng, F.; Li, H.; Li, C.; Wang, L.; Ren, F.; Xie, C.; Wang, P.; et al. Long noncoding RNA FTX is upregulated in gliomas and promotes proliferation and invasion of glioma cells by negatively regulating miR-342-3p. Lab. Investig. J. Tech. Methods Pathol. 2017, 97, 447-457. [CrossRef]

60. Zhao, H.; Peng, R.; Liu, Q.; Liu, D.; Du, P.; Yuan, J.; Peng, G.; Liao, Y. The lncRNA H19 interacts with miR-140 to modulate glioma growth by targeting iASPP. Arch. Biochem. Biophys. 2016, 610, 1-7. [CrossRef]

61. Zhang, T.; Wang, Y.R.; Zeng, F.; Cao, H.Y.; Zhou, H.D.; Wang, Y.J. LncRNA H19 is overexpressed in glioma tissue, is negatively associated with patient survival, and promotes tumor growth through its derivative miR-675. Eur. Rev. Med. Pharmacol. Sci. 2016, 20, 4891-4897. [PubMed]

62. Li, C.; Lei, B.; Huang, S.; Zheng, M.; Liu, Z.; Li, Z.; Deng, Y. H19 derived microRNA-675 regulates cell proliferation and migration through CDK6 in glioma. Am. J. Transl. Res. 2015, 7, 1747-1764. [PubMed]

63. Jiang, P.; Wang, P.; Sun, X.; Yuan, Z.; Zhan, R.; Ma, X.; Li, W. Knockdown of long noncoding RNA H19 sensitizes human glioma cells to temozolomide therapy. OncoTargets Ther. 2016, 9, 3501-3509. [CrossRef]

64. Jiang, X.; Yan, Y.; Hu, M.; Chen, X.; Wang, Y.; Dai, Y.; Wu, D.; Wang, Y.; Zhuang, Z.; Xia, H. Increased level of H19 long noncoding RNA promotes invasion, angiogenesis, and stemness of glioblastoma cells. J. Neurosurg. 2016, 124, 129-136. [CrossRef] [PubMed] 
65. Jia, P.; Cai, H.; Liu, X.; Chen, J.; Ma, J.; Wang, P.; Liu, Y.; Zheng, J.; Xue, Y. Long non-coding RNA H19 regulates glioma angiogenesis and the biological behavior of glioma-associated endothelial cells by inhibiting microRNA-29a. Cancer Lett. 2016, 381, 359-369. [CrossRef] [PubMed]

66. Wang, G.; Li, Z.; Tian, N.; Han, L.; Fu, Y.; Guo, Z.; Tian, Y. miR-148b-3p inhibits malignant biological behaviors of human glioma cells induced by high HOTAIR expression. Oncol. Lett. 2016, 12, 879-886. [CrossRef] [PubMed]

67. Sa, L.; Li, Y.; Zhao, L.; Liu, Y.; Wang, P.; Liu, L.; Li, Z.; Ma, J.; Cai, H.; Xue, Y. The Role of HOTAIR/miR-148b-3p/USF1 on Regulating the Permeability of BTB. Front. Mol. Neurosci. 2017, 10, 194. [CrossRef] [PubMed]

68. Pastori, C.; Kapranov, P.; Penas, C.; Peschansky, V.; Volmar, C.H.; Sarkaria, J.N.; Bregy, A.; Komotar, R.; St Laurent, G.; Ayad, N.G.; et al. The Bromodomain protein BRD4 controls HOTAIR, a long noncoding RNA essential for glioblastoma proliferation. Proc. Natl. Acad. Sci. USA 2015, 112, 8326-8331. [CrossRef]

69. Ke, J.; Yao, Y.L.; Zheng, J.; Wang, P.; Liu, Y.H.; Ma, J.; Li, Z.; Liu, X.B.; Li, Z.Q.; Wang, Z.H.; et al. Knockdown of long non-coding RNA HOTAIR inhibits malignant biological behaviors of human glioma cells via modulation of miR-326. Oncotarget 2015, 6, 21934-21949. [CrossRef]

70. Yang, B.; Wei, Z.Y.; Wang, B.Q.; Yang, H.C.; Wang, J.Y.; Bu, X.Y. Down-regulation of the long noncoding RNA-HOX transcript antisense intergenic RNA inhibits the occurrence and progression of glioma. J. Cell. Biochem. 2017. [CrossRef]

71. Ma, X.; Li, Z.; Li, T.; Zhu, L.; Li, Z.; Tian, N. Long non-coding RNA HOTAIR enhances angiogenesis by induction of VEGFA expression in glioma cells and transmission to endothelial cells via glioma cell derived-extracellular vesicles. Am. J. Transl. Res. 2017, 9, 5012-5021. [PubMed]

72. Xu, L.M.; Chen, L.; Li, F.; Zhang, R.; Li, Z.Y.; Chen, F.F.; Jiang, X.D. Over-expression of the long non-coding RNA HOTTIP inhibits glioma cell growth by BRE. J. Exp. Clin. Cancer Res. CR 2016, 35, 162. [CrossRef] [PubMed]

73. Xu, C.; He, T.; Li, Z.; Liu, H.; Ding, B. Regulation of HOXA11-AS/miR-214-3p/EZH2 axis on the growth, migration and invasion of glioma cells. Biomed. Pharmacother. 2017, 95, 1504-1513. [CrossRef] [PubMed]

74. Cui, Y.; Yi, L.; Zhao, J.Z.; Jiang, Y.G. Long Noncoding RNA HOXA11-AS Functions as miRNA Sponge to Promote the Glioma Tumorigenesis Through Targeting miR-140-5p. DNA Cell Biol. 2017, 36, 822-828. [CrossRef] [PubMed]

75. Wu, F.; Zhang, C.; Cai, J.; Yang, F.; Liang, T.; Yan, X.; Wang, H.; Wang, W.; Chen, J.; Jiang, T. Upregulation of long noncoding RNA HOXA-AS3 promotes tumor progression and predicts poor prognosis in glioma. Oncotarget 2017, 8, 53110-53123. [CrossRef] [PubMed]

76. Yan, H.; Tian, R.; Zhang, M.; Wu, J.; Ding, M.; He, J. High expression of long noncoding RNA HULC is a poor predictor of prognosis and regulates cell proliferation in glioma. OncoTargets Ther. 2017, 10, 113-120. [CrossRef] [PubMed]

77. Zhu, Y.; Zhang, X.; Qi, L.; Cai, Y.; Yang, P.; Xuan, G.; Jiang, Y. HULC long noncoding RNA silencing suppresses angiogenesis by regulating ESM-1 via the PI3K/Akt/mTOR signaling pathway in human gliomas. Oncotarget 2016, 7, 14429-14440. [CrossRef] [PubMed]

78. Hu, G.W.; Wu, L.; Kuang, W.; Chen, Y.; Zhu, X.G.; Guo, H.; Lang, H.L. Knockdown of linc-OIP5 inhibits proliferation and migration of glioma cells through down-regulation of YAP-NOTCH signaling pathway. Gene 2017, 610, 24-31. [CrossRef] [PubMed]

79. Wang, A.; Meng, M.; Zhao, X.; Kong, L. Long non-coding RNA ENST00462717 suppresses the proliferation, survival, and migration by inhibiting MDM2/MAPK pathway in glioma. Biochem. Biophys. Res. Commun. 2017, 485, 513-521. [CrossRef] [PubMed]

80. Ma, J.; Wang, P.; Yao, Y.; Liu, Y.; Li, Z.; Liu, X.; Li, Z.; Zhao, X.; Xi, Z.; Teng, H.; et al. Knockdown of long non-coding RNA MALAT1 increases the blood-tumor barrier permeability by up-regulating miR-140. Biochim. Biophys. Acta 2016, 1859, 324-338. [CrossRef] [PubMed]

81. Fu, Z.; Luo, W.; Wang, J.; Peng, T.; Sun, G.; Shi, J.; Li, Z.; Zhang, B. Malat1 activates autophagy and promotes cell proliferation by sponging miR-101 and upregulating STMN1, RAB5A and ATG4D expression in glioma. Biochem. Biophys. Res. Commun. 2017, 492, 480-486. [CrossRef] [PubMed]

82. Xiang, J.; Guo, S.; Jiang, S.; Xu, Y.; Li, J.; Li, L.; Xiang, J. Silencing of Long Non-Coding RNA MALAT1 Promotes Apoptosis of Glioma Cells. J. Korean Med. Sci. 2016, 31, 688-694. [CrossRef] [PubMed] 
83. Han, Y.; Wu, Z.; Wu, T.; Huang, Y.; Cheng, Z.; Li, X.; Sun, T.; Xie, X.; Zhou, Y.; Du, Z. Tumor-suppressive function of long noncoding RNA MALAT1 in glioma cells by downregulation of MMP2 and inactivation of ERK/MAPK signaling. Cell Death Dis. 2016, 7, e2123. [CrossRef] [PubMed]

84. Cao, S.; Wang, Y.; Li, J.; Lv, M.; Niu, H.; Tian, Y. Tumor-suppressive function of long noncoding RNA MALAT1 in glioma cells by suppressing miR-155 expression and activating FBXW7 function. Am. J. Cancer Res. 2016, 6, 2561-2574. [PubMed]

85. Chen, W.; Xu, X.K.; Li, J.L.; Kong, K.K.; Li, H.; Chen, C.; He, J.; Wang, F.; Li, P.; Ge, X.S.; et al. MALAT1 is a prognostic factor in glioblastoma multiforme and induces chemoresistance to temozolomide through suppressing miR-203 and promoting thymidylate synthase expression. Oncotarget 2017, 8, 22783-22799. [CrossRef] [PubMed]

86. Yue, H.; Zhu, J.; Xie, S.; Li, F.; Xu, Q. MDC1-AS, an antisense long noncoding RNA, regulates cell proliferation of glioma. Biomed. Pharmacother. 2016, 81, 203-209. [CrossRef] [PubMed]

87. Tong, G.F.; Qin, N.; Sun, L.W.; Xu, X.L. Long Noncoding RNA MEG3 Suppresses Glioma Cell Proliferation, Migration, and Invasion By Acting As Competing Endogenous RNA of MiR-19a. Oncol. Res. 2017. [CrossRef]

88. Wu, X.; Wang, Y.; Yu, T.; Nie, E.; Hu, Q.; Wu, W.; Zhi, T.; Jiang, K.; Wang, X.; Lu, X.; et al. Blocking MIR155HG/miR-155 axis inhibits mesenchymal transition in glioma. Neuro-Oncology 2017, 19, 1195-1205. [CrossRef] [PubMed]

89. Min, W.; Dai, D.; Wang, J.; Zhang, D.; Zhang, Y.; Han, G.; Zhang, L.; Chen, C.; Li, X.; Li, Y.; et al. Long Noncoding RNA miR210HG as a Potential Biomarker for the Diagnosis of Glioma. PLoS ONE 2016, 11, e0160451. [CrossRef] [PubMed]

90. Zhuang, J.J.; Yue, M.; Zheng, Y.H.; Li, J.P.; Dong, X.Y. Long non-coding RNA MVIH acts as a prognostic marker in glioma and its role in cell migration and invasion. Eur. Rev. Med. Pharmacol. Sci. 2016, 20, 4898-4904. [PubMed]

91. Guo, J.; Cai, H.; Zheng, J.; Liu, X.; Liu, Y.; Ma, J.; Que, Z.; Gong, W.; Gao, Y.; Tao, W.; et al. Long non-coding RNA NEAT1 regulates permeability of the blood-tumor barrier via miR-181d-5p-mediated expression changes in ZO-1, occludin, and claudin-5. Biochim. Biophys. Acta 2017, 1863, 2240-2254. [CrossRef] [PubMed]

92. He, C.; Jiang, B.; Ma, J.; Li, Q. Aberrant NEAT1 expression is associated with clinical outcome in high grade glioma patients. APMIS Acta Pathol. Microbiol. Immunol. Scand. 2016, 124, 169-174. [CrossRef] [PubMed]

93. Yang, X.; Xiao, Z.; Du, X.; Huang, L.; Du, G. Silencing of the long non-coding RNA NEAT1 suppresses glioma stem-like properties through modulation of the miR-107/CDK6 pathway. Oncol. Rep. 2017, 37, 555-562. [CrossRef] [PubMed]

94. Zhen, L.; Yun-Hui, L.; Hong-Yu, D.; Jun, M.; Yi-Long, Y. Long noncoding RNA NEAT1 promotes glioma pathogenesis by regulating miR-449b-5p/c-Met axis. Tumour Biol. J. Int. Soc. Oncodev. Biol. Med. 2016, 37, 673-683. [CrossRef] [PubMed]

95. Gong, W.; Zheng, J.; Liu, X.; Ma, J.; Liu, Y.; Xue, Y. Knockdown of NEAT1 restrained the malignant progression of glioma stem cells by activating microRNA let-7e. Oncotarget 2016, 7, 62208-62223. [CrossRef] [PubMed]

96. Guo, H.; Wu, L.; Yang, Q.; Ye, M.; Zhu, X. Functional linc-POU3F3 is overexpressed and contributes to tumorigenesis in glioma. Gene 2015, 554, 114-119. [CrossRef] [PubMed]

97. Zou, H.; Wu, L.X.; Yang, Y.; Li, S.; Mei, Y.; Liu, Y.B.; Zhang, L.; Cheng, Y.; Zhou, H.H. lncRNAs PVT1 and HAR1A are prognosis biomarkers and indicate therapy outcome for diffuse glioma patients. Oncotarget 2017, 8, 78767-78780. [CrossRef] [PubMed]

98. Xue, W.; Chen, J.; Liu, X.; Gong, W.; Zheng, J.; Guo, X.; Liu, Y.; Liu, L.; Ma, J.; Wang, P.; et al. PVT1 regulates the malignant behaviors of human glioma cells by targeting miR-190a-5p and miR-488-3p. Biochim. Biophys. Acta 2018, 1864, 1783-1794. [CrossRef] [PubMed]

99. Ma, Y.; Wang, P.; Xue, Y.; Qu, C.; Zheng, J.; Liu, X.; Ma, J.; Liu, Y. PVT1 affects growth of glioma microvascular endothelial cells by negatively regulating miR-186. Tumour Biol. J. Int. Soc. Oncodev. Biol. Med. 2017, 39, 1010428317694326. [CrossRef] [PubMed]

100. Yang, A.; Wang, H.; Yang, X. Long non-coding RNA PVT1 indicates a poor prognosis of glioma and promotes cell proliferation and invasion via target EZH2. Biosci. Rep. 2017, 37. [CrossRef] [PubMed]

101. Zhou, Y.; Wang, D.L.; Pang, Q. Long noncoding RNA SPRY4-IT1 is a prognostic factor for poor overall survival and has an oncogenic role in glioma. Eur. Rev. Med. Pharmacol. Sci. 2016, 20, 3035-3039. [PubMed]

102. Chen, X.; Gao, Y.; Li, D.; Cao, Y.; Hao, B. LncRNA-TP53TG1 Participated in the Stress Response Under Glucose Deprivation in Glioma. J. Cell. Biochem. 2017, 118, 4897-4904. [CrossRef] [PubMed] 
103. Zhang, R.; Jin, H.; Lou, F. The long non-coding RNA TP73-AS1 interacted with miR-142 to modulate brain glioma growth through HMGB1/RAGE pathway. J. Cell. Biochem. 2017. [CrossRef] [PubMed]

104. Qin, X.; Yao, J.; Geng, P.; Fu, X.; Xue, J.; Zhang, Z. LncRNA TSLC1-AS1 is a novel tumor suppressor in glioma. Int. J. Clin. Exp. Pathol. 2014, 7, 3065-3072. [PubMed]

105. Cai, H.; Xue, Y.; Wang, P.; Wang, Z.; Li, Z.; Hu, Y.; Li, Z.; Shang, X.; Liu, Y. The long noncoding RNA TUG1 regulates blood-tumor barrier permeability by targeting miR-144. Oncotarget 2015, 6, 19759-19779. [CrossRef] [PubMed]

106. Li, J.; Zhang, M.; An, G.; Ma, Q. LncRNA TUG1 acts as a tumor suppressor in human glioma by promoting cell apoptosis. Exp. Biol. Med. 2016, 241, 644-649. [CrossRef] [PubMed]

107. Li, J.; An, G.; Zhang, M.; Ma, Q. Long non-coding RNA TUG1 acts as a miR-26a sponge in human glioma cells. Biochem. Biophys. Res. Commun. 2016, 477, 743-748. [CrossRef] [PubMed]

108. Shang, C.; Guo, Y.; Hong, Y.; Xue, Y.X. Long Non-coding RNA TUSC7, a Target of miR-23b, Plays Tumor-Suppressing Roles in Human Gliomas. Front. Cell. Neurosci. 2016, 10, 235. [CrossRef]

109. Sun, Y.; Jin, J.G.; Mi, W.Y.; Wu, H.; Zhang, S.R.; Meng, Q.; Zhang, S.T. Long Non-coding RNA UCA1 Targets miR-122 to Promote Proliferation, Migration, and Invasion of Glioma Cells. Oncol. Res. 2017. [CrossRef]

110. Zhao, W.; Sun, C.; Cui, Z. A long noncoding RNA UCA1 promotes proliferation and predicts poor prognosis in glioma. Clin. Transl. Oncol. Off. Publ. Fed. Span. Oncol. Soc. Natl. Cancer Inst. Mex. 2017, 19, 735-741. [CrossRef]

111. He, Z.; Wang, Y.; Huang, G.; Wang, Q.; Zhao, D.; Chen, L. The lncRNA UCA1 interacts with miR-182 to modulate glioma proliferation and migration by targeting iASPP. Arch. Biochem. Biophys. 2017, 623-624, 1-8. [CrossRef] [PubMed]

112. Wang, Z.; Yuan, J.; Li, L.; Yang, Y.; Xu, X.; Wang, Y. Long non-coding RNA XIST exerts oncogenic functions in human glioma by targeting miR-137. Am. J. Transl. Res. 2017, 9, 1845-1855. [PubMed]

113. Yu, H.; Xue, Y.; Wang, P.; Liu, X.; Ma, J.; Zheng, J.; Li, Z.; Li, Z.; Cai, H.; Liu, Y. Knockdown of long non-coding RNA XIST increases blood-tumor barrier permeability and inhibits glioma angiogenesis by targeting miR-137. Oncogenesis 2017, 6, e303. [CrossRef] [PubMed]

114. Yao, Y.; Ma, J.; Xue, Y.; Wang, P.; Li, Z.; Liu, J.; Chen, L.; Xi, Z.; Teng, H.; Wang, Z.; et al. Knockdown of long non-coding RNA XIST exerts tumor-suppressive functions in human glioblastoma stem cells by up-regulating miR-152. Cancer Lett. 2015, 359, 75-86. [CrossRef] [PubMed]

115. Cheng, Z.; Li, Z.; Ma, K.; Li, X.; Tian, N.; Duan, J.; Xiao, X.; Wang, Y. Long Non-coding RNA XIST Promotes Glioma Tumorigenicity and Angiogenesis by Acting as a Molecular Sponge of miR-429. J. Cancer 2017, 8, 4106-4116. [CrossRef] [PubMed]

116. Du, P.; Zhao, H.; Peng, R.; Liu, Q.; Yuan, J.; Peng, G.; Liao, Y. LncRNA-XIST interacts with miR-29c to modulate the chemoresistance of glioma cell to TMZ through DNA mismatch repair pathway. Biosci. Rep. 2017, 37. [CrossRef] [PubMed]

117. Lv, Q.L.; Hu, L.; Chen, S.H.; Sun, B.; Fu, M.L.; Qin, C.Z.; Qu, Q.; Wang, G.H.; He, C.J.; Zhou, H.H. A Long Noncoding RNA ZEB1-AS1 Promotes Tumorigenesis and Predicts Poor Prognosis in Glioma. Int. J. Mol. Sci. 2016, 17, 1431. [CrossRef]

118. Gao, K.; Ji, Z.; She, K.; Yang, Q.; Shao, L. Long non-coding RNA ZFAS1 is an unfavourable prognostic factor and promotes glioma cell progression by activation of the Notch signaling pathway. Biomed. Pharmacother. 2017, 87, 555-560. [CrossRef]

119. Pervan, C.L. Smad-independent TGF-beta2 signaling pathways in human trabecular meshwork cells. Exp. Eye Res. 2017, 158, 137-145. [CrossRef]

120. Chen, L.; Wang, Y.; He, J.; Zhang, C.; Chen, J.; Shi, D. Long non-coding RNA H19 promotes proliferation and invasion in human glioma cells by downregulating miR-152. Oncol. Res. 2018. [CrossRef]

121. Chen, L.; Zhang, J.; Feng, Y.; Li, R.; Sun, X.; Du, W.; Piao, X.; Wang, H.; Yang, D.; Sun, Y.; et al. MiR-410 regulates MET to influence the proliferation and invasion of glioma. Int. J. Biochem. Cell Biol. 2012, 44, 1711-1717. [CrossRef] [PubMed]

122. Grieco, L.; Calzone, L.; Bernard-Pierrot, I.; Radvanyi, F.; Kahn-Perles, B.; Thieffry, D. Integrative modelling of the influence of MAPK network on cancer cell fate decision. PLoS Comput. Biol. 2013, 9, e1003286. [CrossRef]

123. Sohun, M.; Shen, H. The implication and potential applications of high-mobility group box 1 protein in breast cancer. Ann. Transl. Med. 2016, 4, 217. [CrossRef] [PubMed] 
124. Zang, W.; Wang, T.; Wang, Y.; Chen, X.; Du, Y.; Sun, Q.; Li, M.; Dong, Z.; Zhao, G. Knockdown of long non-coding RNA TP73-AS1 inhibits cell proliferation and induces apoptosis in esophageal squamous cell carcinoma. Oncotarget 2016, 7, 19960-19974. [CrossRef] [PubMed]

125. Bid, H.K.; Roberts, R.D.; Manchanda, P.K.; Houghton, P.J. RAC1: An emerging therapeutic option for targeting cancer angiogenesis and metastasis. Mol. Cancer Ther. 2013, 12, 1925-1934. [CrossRef]

126. Zhang, K.; Sun, X.; Zhou, X.; Han, L.; Chen, L.; Shi, Z.; Zhang, A.; Ye, M.; Wang, Q.; Liu, C.; et al. Long non-coding RNA HOTAIR promotes glioblastoma cell cycle progression in an EZH2 dependent manner. Oncotarget 2015, 6, 537-546. [CrossRef]

127. Roth, P.; Wischhusen, J.; Happold, C.; Chandran, P.A.; Hofer, S.; Eisele, G.; Weller, M.; Keller, A. A specific miRNA signature in the peripheral blood of glioblastoma patients. J. Neurochem. 2011, 118, 449-457. [CrossRef]

128. Sun, J.; Ji, J.; Huo, G.; Song, Q.; Zhang, X. miR-182 induces cervical cancer cell apoptosis through inhibiting the expression of DNMT3a. Int. J. Clin. Exp. Pathol. 2015, 8, 4755-4763.

129. Jin, Y.; Wang, J.; Han, J.; Luo, D.; Sun, Z. MiR-122 inhibits epithelial-mesenchymal transition in hepatocellular carcinoma by targeting Snail1 and Snail2 and suppressing WNT/beta-cadherin signaling pathway. Exp. Cell Res. 2017. [CrossRef]

130. Wang, G.; Zhao, Y.; Zheng, Y. MiR-122/Wnt/beta-catenin regulatory circuitry sustains glioma progression. Tumour Biol. J. Int. Soc. Oncodev. Biol. Med. 2014, 35, 8565-8572. [CrossRef]

131. Zhang, F.; Wan, M.; Xu, Y.; Li, Z.; Leng, K.; Kang, P.; Cui, Y.; Jiang, X. Long noncoding RNA PCAT1 regulates extrahepatic cholangiocarcinoma progression via the Wnt/beta-catenin-signaling pathway. Biomed. Pharmacother. 2017, 94, 55-62. [CrossRef] [PubMed]

132. Lungu, G.; Covaleda, L.; Mendes, O.; Martini-Stoica, H.; Stoica, G. FGF-1-induced matrix metalloproteinase-9 expression in breast cancer cells is mediated by increased activities of NF-kappaB and activating protein-1. Mol. Carcinog. 2008, 47, 424-435. [CrossRef] [PubMed]

133. Hu, Y.; Li, Y.; Wu, C.; Zhou, L.; Han, X.; Wang, Q.; Xie, X.; Zhou, Y.; Du, Z. MicroRNA-140-5p inhibits cell proliferation and invasion by regulating VEGFA/MMP2 signaling in glioma. Tumour Biol. J. Int. Soc. Oncodev. Biol. Med. 2017, 39, 1010428317697558. [CrossRef]

134. Balasubramaniyan, V.; Bhat, K.P. Targeting MIR155HG in glioma: A novel approach. Neuro-Oncology 2017, 19, 1152-1153. [CrossRef] [PubMed]

135. Yang, C.H.; Yue, J.; Pfeffer, S.R.; Handorf, C.R.; Pfeffer, L.M. MicroRNA miR-21 regulates the metastatic behavior of B16 melanoma cells. J. Biol. Chem. 2011, 286, 39172-39178. [CrossRef] [PubMed]

136. Papagiannakopoulos, T.; Shapiro, A.; Kosik, K.S. MicroRNA-21 targets a network of key tumor-suppressive pathways in glioblastoma cells. Cancer Res. 2008, 68, 8164-8172. [CrossRef] [PubMed]

137. Shi, W.; Tang, M.K.; Yao, Y.; Tang, C.; Chui, Y.L.; Lee, K.K. BRE plays an essential role in preventing replicative and DNA damage-induced premature senescence. Sci. Rep. 2016, 6, 23506. [CrossRef]

138. Zhang, S.; Wang, W.; Liu, G.; Xie, S.; Li, Q.; Li, Y.; Lin, Z. Long non-coding RNA HOTTIP promotes hypoxia-induced epithelial-mesenchymal transition of malignant glioma by regulating the miR-101/ZEB1 axis. Biomed. Pharmacother. 2017, 95, 711-720. [CrossRef]

139. Guo, P.; Nie, Q.; Lan, J.; Ge, J.; Qiu, Y.; Mao, Q. C-Myc negatively controls the tumor suppressor PTEN by upregulating miR-26a in glioblastoma multiforme cells. Biochem. Biophys. Res. Commun. 2013, 441, 186-190. [CrossRef]

140. Jiang, J.; Yang, J.; Wang, Z.; Wu, G.; Liu, F. TFAM is directly regulated by miR-23b in glioma. Oncol. Rep. 2013, 30, 2105-2110. [CrossRef]

141. Sun, J.; Jia, Z.; Li, B.; Zhang, A.; Wang, G.; Pu, P.; Chen, Z.; Wang, Z.; Yang, W. MiR-19 regulates the proliferation and invasion of glioma by RUNX3 via beta-catenin/Tcf-4 signaling. Oncotarget 2017, 8 , 110785-110796. [CrossRef] [PubMed]

142. Shi, Y.; Tao, T.; Liu, N.; Luan, W.; Qian, J.; Li, R.; Hu, Q.; Wei, Y.; Zhang, J.; You, Y. PPARalpha, a predictor of patient survival in glioma, inhibits cell growth through the E2F1/miR-19a feedback loop. Oncotarget 2016, 7, 84623-84633. [CrossRef] [PubMed]

143. Luo, G.; Luo, W.; Sun, X.; Lin, J.; Wang, M.; Zhang, Y.; Luo, W.; Zhang, Y. MicroRNA21 promotes migration and invasion of glioma cells via activation of Sox2 and betacatenin signaling. Mol. Med. Rep. 2017, 15, 187-193. [CrossRef] [PubMed] 
144. Chen, W.; Yu, Q.; Chen, B.; Lu, X.; Li, Q. The prognostic value of a seven-microRNA classifier as a novel biomarker for the prediction and detection of recurrence in glioma patients. Oncotarget 2016, 7, 53392-53413. [CrossRef] [PubMed]

145. Hermansen, S.K.; Nielsen, B.S.; Aaberg-Jessen, C.; Kristensen, B.W. miR-21 Is Linked to Glioma Angiogenesis: A Co-Localization Study. J. Histochem. Cytochem. 2016, 64, 138-148. [CrossRef] [PubMed]

146. Wang, G.B.; Liu, J.H.; Hu, J.; Xue, K. MiR-21 enhanced glioma cells resistance to carmustine via decreasing Spry2 expression. Eur. Rev. Med. Pharmacol. Sci. 2017, 21, 5065-5071. [CrossRef] [PubMed]

147. Rani, S.B.; Rathod, S.S.; Karthik, S.; Kaur, N.; Muzumdar, D.; Shiras, A.S. MiR-145 functions as a tumor-suppressive RNA by targeting Sox 9 and adducin 3 in human glioma cells. Neuro-Oncology 2013, 15, 1302-1316. [CrossRef] [PubMed]

148. Du, Y.; Li, J.; Xu, T.; Zhou, D.D.; Zhang, L.; Wang, X. MicroRNA-145 induces apoptosis of glioma cells by targeting BNIP3 and Notch signaling. Oncotarget 2017, 8, 61510-61527. [CrossRef]

149. Morgado, A.L.; Rodrigues, C.M.; Sola, S. MicroRNA-145 Regulates Neural Stem Cell Differentiation Through the Sox2-Lin28/let-7 Signaling Pathway. Stem Cells 2016, 34, 1386-1395. [CrossRef]

150. Xu, G.; Li, J.Y. Differential expression of PDGFRB and EGFR in microvascular proliferation in glioblastoma. Tumour Biol. J. Int. Soc. Oncodev. Biol. Med. 2016, 37, 10577-10586. [CrossRef]

151. Kim, H.; Huang, W.; Jiang, X.; Pennicooke, B.; Park, P.J.; Johnson, M.D. Integrative genome analysis reveals an oncomir/oncogene cluster regulating glioblastoma survivorship. Proc. Natl. Acad. Sci. USA 2010, 107, 2183-2188. [CrossRef] [PubMed]

152. Aldaz, B.; Sagardoy, A.; Nogueira, L.; Guruceaga, E.; Grande, L.; Huse, J.T.; Aznar, M.A.; Diez-Valle, R.; Tejada-Solis, S.; Alonso, M.M.; et al. Involvement of miRNAs in the differentiation of human glioblastoma multiforme stem-like cells. PLoS ONE 2013, 8, e77098. [CrossRef] [PubMed]

153. Xi, Z.; Wang, P.; Xue, Y.; Shang, C.; Liu, X.; Ma, J.; Li, Z.; Li, Z.; Bao, M.; Liu, Y. Overexpression of miR-29a reduces the oncogenic properties of glioblastoma stem cells by downregulating Quaking gene isoform 6 . Oncotarget 2017, 8, 24949-24963. [CrossRef] [PubMed]

154. Xiao, S.; Yang, Z.; Qiu, X.; Lv, R.; Liu, J.; Wu, M.; Liao, Y.; Liu, Q. miR-29c contribute to glioma cells temozolomide sensitivity by targeting O6-methylguanine-DNA methyltransferases indirectely. Oncotarget 2016, 7, 50229-50238. [CrossRef] [PubMed]

155. Liu, X.; Lei, Q.; Yu, Z.; Xu, G.; Tang, H.; Wang, W.; Wang, Z.; Li, G.; Wu, M. MiR-101 reverses the hypomethylation of the LMO3 promoter in glioma cells. Oncotarget 2015, 6, 7930-7943. [CrossRef] [PubMed]

156. Ma, C.; Zheng, C.; Bai, E.; Yang, K. miR-101 inhibits glioma cell invasion via the downregulation of COX-2. Oncol. Lett. 2016, 12, 2538-2544. [CrossRef] [PubMed]

157. Liu, N.; Zhang, L.; Wang, Z.; Cheng, Y.; Zhang, P.; Wang, X.; Wen, W.; Yang, H.; Liu, H.; Jin, W.; et al. MicroRNA-101 inhibits proliferation, migration and invasion of human glioblastoma by targeting SOX9. Oncotarget 2017, 8, 19244-19254. [CrossRef] [PubMed]

158. Tian, T.; Mingyi, M.; Qiu, X.; Qiu, Y. MicroRNA-101 reverses temozolomide resistance by inhibition of GSK3beta in glioblastoma. Oncotarget 2016, 7, 79584-79595. [CrossRef] [PubMed]

159. Chen, L.; Chen, X.R.; Zhang, R.; Li, P.; Liu, Y.; Yan, K.; Jiang, X.D. MicroRNA-107 inhibits glioma cell migration and invasion by modulating Notch2 expression. J. Neuro-Oncol. 2013, 112, 59-66. [CrossRef] [PubMed]

160. Chen, L.; Chen, X.R.; Chen, F.F.; Liu, Y.; Li, P.; Zhang, R.; Yan, K.; Yi, Y.J.; Xu, Z.M.; Jiang, X.D. MicroRNA-107 inhibits U87 glioma stem cells growth and invasion. Cell. Mol. Neurobiol. 2013, 33, 651-657. [CrossRef] [PubMed]

161. He, J.; Zhang, W.; Zhou, Q.; Zhao, T.; Song, Y.; Chai, L.; Li, Y. Low-expression of microRNA-107 inhibits cell apoptosis in glioma by upregulation of SALL4. Int. J. Biochem. Cell Biol. 2013, 45, 1962-1973. [CrossRef] [PubMed]

162. Chen, L.; Li, Z.Y.; Xu, S.Y.; Zhang, X.J.; Zhang, Y.; Luo, K.; Li, W.P. Upregulation of miR-107 Inhibits Glioma Angiogenesis and VEGF Expression. Cell. Mol. Neurobiol. 2016, 36, 113-120. [CrossRef] [PubMed]

163. Ji, Y.; Wei, Y.; Wang, J.; Ao, Q.; Gong, K.; Zuo, H. Decreased expression of microRNA-107 predicts poorer prognosis in glioma. Tumour Biol. J. Int. Soc. Oncodev. Biol. Med. 2015, 36, 4461-4466. [CrossRef] [PubMed]

164. Su, R.; Cao, S.; Ma, J.; Liu, Y.; Liu, X.; Zheng, J.; Chen, J.; Liu, L.; Cai, H.; Li, Z.; et al. Knockdown of SOX2OT inhibits the malignant biological behaviors of glioblastoma stem cells via up-regulating the expression of miR-194-5p and miR-122. Mol. Cancer 2017, 16, 171. [CrossRef] [PubMed] 
165. Yerukala Sathipati, S.; Huang, H.L.; Ho, S.Y. Estimating survival time of patients with glioblastoma multiforme and characterization of the identified microRNA signatures. BMC Genom. 2016, 17, 1022. [CrossRef] [PubMed]

166. Sun, G.; Cao, Y.; Shi, L.; Sun, L.; Wang, Y.; Chen, C.; Wan, Z.; Fu, L.; You, Y. Overexpressed miRNA-137 inhibits human glioma cells growth by targeting Rac1. Cancer Biother. Radiopharm. 2013, 28, 327-334. [CrossRef]

167. Li, H.Y.; Li, Y.M.; Li, Y.; Shi, X.W.; Chen, H. Circulating microRNA-137 is a potential biomarker for human glioblastoma. Eur. Rev. Med. Pharmacol. Sci. 2016, 20, 3599-3604.

168. Sun, J.; Zheng, G.; Gu, Z.; Guo, Z. MiR-137 inhibits proliferation and angiogenesis of human glioblastoma cells by targeting EZH2. J. Neuro-Oncol. 2015, 122, 481-489. [CrossRef]

169. Liu, X.; Wang, S.; Yuan, A.; Yuan, X.; Liu, B. MicroRNA-140 represses glioma growth and metastasis by directly targeting ADAM9. Oncol. Rep. 2016, 36, 2329-2338. [CrossRef]

170. Li, G.; Yang, H.; Han, K.; Zhu, D.; Lun, P.; Zhao, Y. A novel circular RNA, hsa_circ_0046701, promotes carcinogenesis by increasing the expression of miR-142-3p target ITGB8 in glioma. Biochem. Biophys. Res. Commun. 2018, 498, 254-261. [CrossRef]

171. Qin, W.; Rong, X.; Dong, J.; Yu, C.; Yang, J. miR-142 inhibits the migration and invasion of glioma by targeting Rac1. Oncol. Rep. 2017, 38, 1543-1550. [CrossRef] [PubMed]

172. Lan, F.; Yu, H.; Hu, M.; Xia, T.; Yue, X. miR-144-3p exerts anti-tumor effects in glioblastoma by targeting c-Met. J. Neurochem. 2015, 135, 274-286. [CrossRef] [PubMed]

173. Zheng, X.; Chopp, M.; Lu, Y.; Buller, B.; Jiang, F. MiR-15b and miR-152 reduce glioma cell invasion and angiogenesis via NRP-2 and MMP-3. Cancer Lett. 2013, 329, 146-154. [CrossRef] [PubMed]

174. Zhang, P.; Sun, H.; Yang, B.; Luo, W.; Liu, Z.; Wang, J.; Zuo, Y. miR-152 regulated glioma cell proliferation and apoptosis via Runx2 mediated by DNMT1. Biomed. Pharmacother. 2017, 92, 690-695. [CrossRef] [PubMed]

175. Sun, J.; Tian, X.; Zhang, J.; Huang, Y.; Lin, X.; Chen, L.; Zhang, S. Regulation of human glioma cell apoptosis and invasion by miR-152-3p through targeting DNMT1 and regulating NF2: MiR-152-3p regulate glioma cell apoptosis and invasion. J. Exp. Clin. Cancer Res. CR 2017, 36, 100. [CrossRef] [PubMed]

176. Yan, Z.; Che, S.; Wang, J.; Jiao, Y.; Wang, C.; Meng, Q. miR-155 contributes to the progression of glioma by enhancing Wnt/beta-catenin pathway. Tumour Biol. J. Int. Soc. Oncodev. Biol. Med. 2015, 36, 5323-5331. [CrossRef] [PubMed]

177. Liu, Q.; Zou, R.; Zhou, R.; Gong, C.; Wang, Z.; Cai, T.; Tan, C.; Fang, J. miR-155 Regulates Glioma Cells Invasion and Chemosensitivity by p38 Isforms In Vitro. J. Cell. Biochem. 2015, 116, 1213-1221. [CrossRef] [PubMed]

178. Zhou, Y.; Peng, Y.; Liu, M.; Jiang, Y. MicroRNA-181b Inhibits Cellular Proliferation and Invasion of Glioma Cells via Targeting Sal-Like Protein 4. Oncol. Res. 2017, 25, 947-957. [CrossRef] [PubMed]

179. Li, P.; Lu, X.; Wang, Y.; Sun, L.; Qian, C.; Yan, W.; Liu, N.; You, Y.; Fu, Z. MiR-181b suppresses proliferation of and reduces chemoresistance to temozolomide in U87 glioma stem cells. J. Biomed. Res. 2010, 24, 436-443. [CrossRef]

180. Shi, Z.M.; Wang, X.F.; Qian, X.; Tao, T.; Wang, L.; Chen, Q.D.; Wang, X.R.; Cao, L.; Wang, Y.Y.; Zhang, J.X.; et al. MiRNA-181b suppresses IGF-1R and functions as a tumor suppressor gene in gliomas. RNA 2013, 19, 552-560. [CrossRef]

181. Sun, Y.C.; Wang, J.; Guo, C.C.; Sai, K.; Wang, J.; Chen, F.R.; Yang, Q.Y.; Chen, Y.S.; Wang, J.; To, T.S.; et al. MiR-181b sensitizes glioma cells to teniposide by targeting MDM2. BMC Cancer 2014, 14, 611. [CrossRef]

182. Ho, K.H.; Chen, P.H.; Hsi, E.; Shih, C.M.; Chang, W.C.; Cheng, C.H.; Lin, C.W.; Chen, K.C. Identification of IGF-1-enhanced cytokine expressions targeted by miR-181d in glioblastomas via an integrative miRNA/mRNA regulatory network analysis. Sci. Rep. 2017, 7, 732. [CrossRef] [PubMed]

183. Wang, X.F.; Shi, Z.M.; Wang, X.R.; Cao, L.; Wang, Y.Y.; Zhang, J.X.; Yin, Y.; Luo, H.; Kang, C.S.; Liu, N.; et al. MiR-181d acts as a tumor suppressor in glioma by targeting K-ras and Bcl-2. J. Cancer Res. Clin. Oncol. 2012, 138, 573-584. [CrossRef] [PubMed]

184. Zhang, W.; Zhang, J.; Hoadley, K.; Kushwaha, D.; Ramakrishnan, V.; Li, S.; Kang, C.; You, Y.; Jiang, C.; Song, S.W.; et al. miR-181d: A predictive glioblastoma biomarker that downregulates MGMT expression. Neuro-Oncology 2012, 14, 712-719. [CrossRef]

185. Ma, J.; Yao, Y.; Wang, P.; Liu, Y.; Zhao, L.; Li, Z.; Li, Z.; Xue, Y. MiR-181a regulates blood-tumor barrier permeability by targeting Kruppel-like factor 6. J. Cerebr. Blood Flow Metab. 2014, 34, 1826-1836. [CrossRef] 
186. Kouri, F.M.; Ritner, C.; Stegh, A.H. miRNA-182 and the regulation of the glioblastoma phenotype-Toward miRNA-based precision therapeutics. Cell Cycle 2015, 14, 3794-3800. [CrossRef]

187. Feng, Y.A.; Liu, T.E.; Wu, Y. microRNA-182 inhibits the proliferation and migration of glioma cells through the induction of neuritin expression. Oncol. Lett. 2015, 10, 1197-1203. [CrossRef]

188. Xue, J.; Zhou, A.; Wu, Y.; Morris, S.A.; Lin, K.; Amin, S.; Verhaak, R.; Fuller, G.; Xie, K.; Heimberger, A.B.; et al. miR-182-5p Induced by STAT3 Activation Promotes Glioma Tumorigenesis. Cancer Res. 2016, 76, 4293-4304. [CrossRef]

189. Xiao, Y.; Zhang, L.; Song, Z.; Guo, C.; Zhu, J.; Li, Z.; Zhu, S. Potential Diagnostic and Prognostic Value of Plasma Circulating MicroRNA-182 in Human Glioma. Med. Sci. Monit. Int. Med. J. Exp. Clin. Res. 2016, 22, 855-862. [CrossRef]

190. Zheng, J.; Li, X.D.; Wang, P.; Liu, X.B.; Xue, Y.X.; Hu, Y.; Li, Z.; Li, Z.Q.; Wang, Z.H.; Liu, Y.H. CRNDE affects the malignant biological characteristics of human glioma stem cells by negatively regulating miR-186. Oncotarget 2015, 6, 25339-25355. [CrossRef]

191. Berthois, Y.; Delfino, C.; Metellus, P.; Fina, F.; Nanni-Metellus, I.; Al Aswy, H.; Pirisi, V.; Ouafik, L.; Boudouresque, F. Differential expression of miR200a-3p and miR21 in grade II-III and grade IV gliomas: Evidence that miR200a-3p is regulated by $\mathrm{O}(6)$-methylguanine methyltransferase and promotes temozolomide responsiveness. Cancer Biol. Ther. 2014, 15, 938-950. [CrossRef] [PubMed]

192. Liao, H.; Bai, Y.; Qiu, S.; Zheng, L.; Huang, L.; Liu, T.; Wang, X.; Liu, Y.; Xu, N.; Yan, X.; et al. MiR-203 downregulation is responsible for chemoresistance in human glioblastoma by promoting epithelial-mesenchymal transition via SNAI2. Oncotarget 2015, 6, 8914-8928. [CrossRef]

193. Pal, D.; Mukhopadhyay, D.; Ramaiah, M.J.; Sarma, P.; Bhadra, U.; Bhadra, M.P. Regulation of Cell Proliferation and Migration by miR-203 via GAS41/miR-10b Axis in Human Glioblastoma Cells. PLoS ONE 2016, 11, e0159092. [CrossRef] [PubMed]

194. Yang, C.H.; Wang, Y.; Sims, M.; Cai, C.; He, P.; Hacker, H.; Yue, J.; Cheng, J.; Boop, F.A.; Pfeffer, L.M. MicroRNA203a suppresses glioma tumorigenesis through an ATM-dependent interferon response pathway. Oncotarget 2017, 8, 112980-112991. [CrossRef] [PubMed]

195. Zhou, J.; Xu, T.; Yan, Y.; Qin, R.; Wang, H.; Zhang, X.; Huang, Y.; Wang, Y.; Lu, Y.; Fu, D.; et al. MicroRNA-326 functions as a tumor suppressor in glioma by targeting the Nin one binding protein (NOB1). PLoS ONE 2013, 8, e68469. [CrossRef] [PubMed]

196. Du, W.; Liu, X.; Chen, L.; Dou, Z.; Lei, X.; Chang, L.; Cai, J.; Cui, Y.; Yang, D.; Sun, Y.; et al. Targeting the SMO oncogene by miR-326 inhibits glioma biological behaviors and stemness. Neuro-Oncology 2015, 17, $243-253$. [CrossRef] [PubMed]

197. Hu, G.; Wei, Y.; Kang, Y. The multifaceted role of MTDH/AEG-1 in cancer progression. Clin. Cancer Res. Off. J. Am. Assoc. Cancer Res. 2009, 15, 5615-5620. [CrossRef] [PubMed]

198. Wang, Q.; Li, P.; Li, A.; Jiang, W.; Wang, H.; Wang, J.; Xie, K. Plasma specific miRNAs as predictive biomarkers for diagnosis and prognosis of glioma. J. Exp. Clin. Cancer Res. CR 2012, 31, 97. [CrossRef]

199. Chen, L.; Xue, Y.; Zheng, J.; Liu, X.; Liu, J.; Chen, J.; Li, Z.; Xi, Z.; Teng, H.; Wang, P.; et al. MiR-429 Regulated by Endothelial Monocyte Activating Polypeptide-II (EMAP-II) Influences Blood-Tumor Barrier Permeability by Inhibiting the Expressions of ZO-1, Occludin and Claudin-5. Front. Mol. Neurosci. 2018, 11, 35. [CrossRef]

200. Dong, H.; Hao, X.; Cui, B.; Guo, M. MiR-429 suppresses glioblastoma multiforme by targeting SOX2. Cell Biochem. Funct. 2017, 35, 260-268. [CrossRef]

201. Hu, C.E.; Du, P.Z.; Zhang, H.D.; Huang, G.J. Long Noncoding RNA CRNDE Promotes Proliferation of Gastric Cancer Cells by Targeting miR-145. Cell. Physiol. Biochem. Int. J. Exp. Cell. Physiol. Biochem. Pharmacol. 2017, 42, 13-21. [CrossRef] [PubMed]

202. Liu, C.; Sun, Y.; She, X.; Tu, C.; Cheng, X.; Wang, L.; Yu, Z.; Li, P.; Liu, Q.; Yang, H.; et al. CASC2c as an unfavorable prognosis factor interacts with miR-101 to mediate astrocytoma tumorigenesis. Cell Death Dis. 2017, 8, e2639. [CrossRef] [PubMed]

203. Pratap, P.; Raza, S.T.; Abbas, S.; Mahdi, F. MicroRNA-associated carcinogenesis in lung carcinoma. J. Cancer Res. Ther. 2018, 14, 249-254. [CrossRef] [PubMed]

204. Chen, Y.; Wei, H.; Liu, Y.; Zheng, S. Promotional effect of microRNA-194 on breast cancer cells via targeting F-box/WD repeat-containing protein 7. Oncol. Lett. 2018, 15, 4439-4444. [CrossRef] [PubMed] 
205. Jia, L.; Tian, Y.; Chen, Y.; Zhang, G. The silencing of LncRNA-H19 decreases chemoresistance of human glioma cells to temozolomide by suppressing epithelial-mesenchymal transition via the Wnt/beta-Catenin pathway. OncoTargets Ther. 2018, 11, 313-321. [CrossRef] [PubMed]

206. Luo, H.; Chen, Z.; Wang, S.; Zhang, R.; Qiu, W.; Zhao, L.; Peng, C.; Xu, R.; Chen, W.; Wang, H.W.; et al. c-Myc-miR-29c-REV3L signalling pathway drives the acquisition of temozolomide resistance in glioblastoma. Brain J. Neurol. 2015, 138, 3654-3672. [CrossRef] [PubMed]

207. Salvador, M.A.; Wicinski, J.; Cabaud, O.; Toiron, Y.; Finetti, P.; Josselin, E.; Lelievre, H.; Kraus-Berthier, L.; Depil, S.; Bertucci, F.; et al. The histone deacetylase inhibitor abexinostat induces cancer stem cells differentiation in breast cancer with low Xist expression. Clin. Cancer Res. 2013, 19, 6520-6531. [CrossRef] [PubMed]

208. Schouten, P.C.; Vollebergh, M.A.; Opdam, M.; Jonkers, M.; Loden, M.; Wesseling, J.; Hauptmann, M.; Linn, S.C. High XIST and Low 53BP1 Expression Predict Poor Outcome after High-Dose Alkylating Chemotherapy in Patients with a BRCA1-like Breast Cancer. Mol. Cancer Ther. 2016, 15, 190-198. [CrossRef]

209. Hanahan, D.; Weinberg, R.A. Hallmarks of cancer: The next generation. Cell 2011, 144, 646-674. [CrossRef]

210. Jain, R.K.; di Tomaso, E.; Duda, D.G.; Loeffler, J.S.; Sorensen, A.G.; Batchelor, T.T. Angiogenesis in brain tumours. Nat. Rev. Neurosci. 2007, 8, 610-622. [CrossRef]

211. Knizhnik, A.V.; Roos, W.P.; Nikolova, T.; Quiros, S.; Tomaszowski, K.H.; Christmann, M.; Kaina, B. Survival and death strategies in glioma cells: Autophagy, senescence and apoptosis triggered by a single type of temozolomide-induced DNA damage. PLOS ONE 2013, 8, e55665. [CrossRef]

212. Shimizu, A.; Nakayama, H.; Wang, P.; Konig, C.; Akino, T.; Sandlund, J.; Coma, S.; Italiano, J.E., Jr.; Mammoto, A.; Bielenberg, D.R.; et al. Netrin-1 promotes glioblastoma cell invasiveness and angiogenesis by multiple pathways including activation of RhoA, cathepsin B, and cAMP-response element-binding protein. J. Biol. Chem. 2013, 288, 2210-2222. [CrossRef]

213. Hardee, M.E.; Zagzag, D. Mechanisms of glioma-associated neovascularization. Am. J. Pathol. 2012, 181, 1126-1141. [CrossRef]

214. Fischbach, C.; Kong, H.J.; Hsiong, S.X.; Evangelista, M.B.; Yuen, W.; Mooney, D.J. Cancer cell angiogenic capability is regulated by 3D culture and integrin engagement. Proc. Natl. Acad. Sci. USA 2009, 106, 399-404. [CrossRef]

215. Huang, W.J.; Chen, W.W.; Zhang, X. Glioblastoma multiforme: Effect of hypoxia and hypoxia inducible factors on therapeutic approaches. Oncol. Lett. 2016, 12, 2283-2288. [CrossRef]

216. Chang, Y.; Wu, Q.; Tian, T.; Li, L.; Guo, X.; Feng, Z.; Zhou, J.; Zhang, L.; Zhou, S.; Feng, G.; et al. The influence of SRPK1 on glioma apoptosis, metastasis, and angiogenesis through the PI3K/Akt signaling pathway under normoxia. Tumour Biol. J. Int. Soc. Oncodev. Biol. Med. 2015, 36, 6083-6093. [CrossRef]

217. Koyanagi, T.; Saga, Y.; Takahashi, Y.; Suzuki, Y.; Suzuki, M.; Sato, Y. Downregulation of vasohibin-2, a novel angiogenesis regulator, suppresses tumor growth by inhibiting angiogenesis in endometrial cancer cells. Oncol. Lett. 2013, 5, 1058-1062. [CrossRef]

218. Koyanagi, T.; Suzuki, Y.; Komori, K.; Saga, Y.; Matsubara, S.; Fujiwara, H.; Sato, Y. Targeting human vasohibin-2 by a neutralizing monoclonal antibody for anti-cancer treatment. Cancer Sci. 2017, 108, 512-519. [CrossRef]

219. Xue, X.; Gao, W.; Sun, B.; Xu, Y.; Han, B.; Wang, F.; Zhang, Y.; Sun, J.; Wei, J.; Lu, Z.; et al. Vasohibin 2 is transcriptionally activated and promotes angiogenesis in hepatocellular carcinoma. Oncogene 2013, 32, 1724-1734. [CrossRef]

220. Lo Dico, A.; Costa, V.; Martelli, C.; Diceglie, C.; Rajata, F.; Rizzo, A.; Mancone, C.; Tripodi, M.; Ottobrini, L.; Alessandro, R.; et al. MiR675-5p Acts on HIF-1alpha to Sustain Hypoxic Responses: A New Therapeutic Strategy for Glioma. Theranostics 2016, 6, 1105-1118. [CrossRef]

221. Lang, H.L.; Hu, G.W.; Chen, Y.; Liu, Y.; Tu, W.; Lu, Y.M.; Wu, L.; Xu, G.H. Glioma cells promote angiogenesis through the release of exosomes containing long non-coding RNA POU3F3. Eur. Rev. Med. Pharmacol. Sci. 2017, 21, 959-972.

222. Ma, Y.; Xue, Y.; Liu, X.; Qu, C.; Cai, H.; Wang, P.; Li, Z.; Li, Z.; Liu, Y. SNHG15 affects the growth of glioma microvascular endothelial cells by negatively regulating miR-153. Oncol. Rep. 2017, 38, 3265-3277. [CrossRef]

223. Bauer, H.; Traweger, A. Tight Junctions of the Blood-Brain Barrier-A Molecular Gatekeeper. CNS Neurol. Disord. Drug Targets 2016, 15, 1016-1029. [CrossRef] 
224. Luissint, A.C.; Artus, C.; Glacial, F.; Ganeshamoorthy, K.; Couraud, P.O. Tight junctions at the blood brain barrier: Physiological architecture and disease-associated dysregulation. Fluids Barriers CNS 2012, 9, 23. [CrossRef]

225. Shen, S.; Yu, H.; Liu, X.; Liu, Y.; Zheng, J.; Wang, P.; Gong, W.; Chen, J.; Zhao, L.; Xue, Y. PIWIL1/piRNA-DQ593109 Regulates the Permeability of the Blood-Tumor Barrier via the MEG3/miR-330-5p/RUNX3 Axis. Mol. Ther. Nucleic Acids 2018, 10, 412-425. [CrossRef]

226. Malzkorn, B.; Reifenberger, G. Practical implications of integrated glioma classification according to the World Health Organization classification of tumors of the central nervous system 2016. Curr. Opin. Oncol. 2016, 28, 494-501. [CrossRef]

227. Kros, J.M.; Mustafa, D.M.; Dekker, L.J.; Sillevis Smitt, P.A.; Luider, T.M.; Zheng, P.P. Circulating glioma biomarkers. Neuro-Oncology 2015, 17, 343-360. [CrossRef]

228. Cheng, W.; Ren, X.; Zhang, C.; Han, S.; Wu, A. Expression and prognostic value of microRNAs in lower-grade glioma depends on IDH1/2 status. J. Neuro-Oncol. 2017, 132, 207-218. [CrossRef]

229. Zhang, X.Q.; Kiang, K.M.; Wang, Y.C.; Pu, J.K.; Ho, A.; Cheng, S.Y.; Lee, D.; Zhang, P.D.; Chen, J.J.; Lui, W.M.; et al. IDH1 mutation-associated long non-coding RNA expression profile changes in glioma. J. Neuro-Oncol. 2015, 125, 253-263. [CrossRef]

230. Jha, P.; Agrawal, R.; Pathak, P.; Kumar, A.; Purkait, S.; Mallik, S.; Suri, V.; Chand Sharma, M.; Gupta, D.; Suri, A.; et al. Genome-wide small noncoding RNA profiling of pediatric high-grade gliomas reveals deregulation of several miRNAs, identifies downregulation of snoRNA cluster HBII-52 and delineates H3F3A and TP53 mutant-specific miRNAs and snoRNAs. Int. J. Cancer 2015, 137, 2343-2353. [CrossRef]

231. Cao, T.; Rajasingh, S.; Samanta, S.; Dawn, B.; Bittel, D.C.; Rajasingh, J. Biology and clinical relevance of noncoding sno/scaRNAs. Trends Cardiovasc. Med. 2017. [CrossRef]

232. Xu, B.; Ye, M.H.; Lv, S.G.; Wang, Q.X.; Wu, M.J.; Xiao, B.; Kang, C.S.; Zhu, X.G. SNORD47, a box C/D snoRNA, suppresses tumorigenesis in glioblastoma. Oncotarget 2017, 8, 43953-43966. [CrossRef]

233. Chen, L.; Han, L.; Wei, J.; Zhang, K.; Shi, Z.; Duan, R.; Li, S.; Zhou, X.; Pu, P.; Zhang, J.; et al. SNORD76, a box C/D snoRNA, acts as a tumor suppressor in glioblastoma. Sci. Rep. 2015, 5, 8588. [CrossRef]

234. Zheng, R.; Yao, Q.; Ren, C.; Liu, Y.; Yang, H.; Xie, G.; Du, S.; Yang, K.; Yuan, Y. Upregulation of Long Noncoding RNA Small Nucleolar RNA Host Gene 18 Promotes Radioresistance of Glioma by Repressing Semaphorin 5A. Int. J. Radiat. Oncol. Biol. Phys. 2016, 96, 877-887. [CrossRef]

235. Wang, Q.; Li, Q.; Zhou, P.; Deng, D.; Xue, L.; Shao, N.; Peng, Y.; Zhi, F. Upregulation of the long non-coding RNA SNHG1 predicts poor prognosis, promotes cell proliferation and invasion, and reduces apoptosis in glioma. Biomed. Pharmacother. 2017, 91, 906-911. [CrossRef]

236. Ronchetti, D.; Mosca, L.; Cutrona, G.; Tuana, G.; Gentile, M.; Fabris, S.; Agnelli, L.; Ciceri, G.; Matis, S.; Massucco, C.; et al. Small nucleolar RNAs as new biomarkers in chronic lymphocytic leukemia. BMC Med. Genom. 2013, 6, 27. [CrossRef]

237. Ronchetti, D.; Todoerti, K.; Tuana, G.; Agnelli, L.; Mosca, L.; Lionetti, M.; Fabris, S.; Colapietro, P.; Miozzo, M.; Ferrarini, M.; et al. The expression pattern of small nucleolar and small Cajal body-specific RNAs characterizes distinct molecular subtypes of multiple myeloma. Blood Cancer J. 2012, 2, e96. [CrossRef]

238. Dong, Y.; He, D.; Peng, Z.; Peng, W.; Shi, W.; Wang, J.; Li, B.; Zhang, C.; Duan, C. Circular RNAs in cancer: An emerging key player. J. Hematol. Oncol. 2017, 10, 2. [CrossRef]

239. Enuka, Y.; Lauriola, M.; Feldman, M.E.; Sas-Chen, A.; Ulitsky, I.; Yarden, Y. Circular RNAs are long-lived and display only minimal early alterations in response to a growth factor. Nucleic Acids Res. 2016, 44, 1370-1383. [CrossRef]

240. Zheng, J.; Liu, X.; Xue, Y.; Gong, W.; Ma, J.; Xi, Z.; Que, Z.; Liu, Y. TTBK2 circular RNA promotes glioma malignancy by regulating miR-217/HNF1beta/Derlin-1 pathway. J. Hematol. Oncol. 2017, 10, 52. [CrossRef]

241. Yang, Y.; Gao, X.; Zhang, M.; Yan, S.; Sun, C.; Xiao, F.; Huang, N.; Yang, X.; Zhao, K.; Zhou, H.; et al. Novel Role of FBXW7 Circular RNA in Repressing Glioma Tumorigenesis. J. Natl. Cancer Inst. 2018, 110. [CrossRef]

242. Yang, P.; Qiu, Z.; Jiang, Y.; Dong, L.; Yang, W.; Gu, C.; Li, G.; Zhu, Y. Silencing of cZNF292 circular RNA suppresses human glioma tube formation via the Wnt/beta-catenin signaling pathway. Oncotarget 2016, 7 , 63449-63455. [CrossRef]

243. Farazi, T.A.; Juranek, S.A.; Tuschl, T. The growing catalog of small RNAs and their association with distinct Argonaute/Piwi family members. Development 2008, 135, 1201-1214. [CrossRef] 
244. Lu, Y.; Zhang, K.; Li, C.; Yao, Y.; Tao, D.; Liu, Y.; Zhang, S.; Ma, Y. Piwil2 suppresses p53 by inducing phosphorylation of signal transducer and activator of transcription 3 in tumor cells. PLoS ONE 2012, 7, e30999. [CrossRef]

245. Zhong, F.; Zhou, N.; Wu, K.; Guo, Y.; Tan, W.; Zhang, H.; Zhang, X.; Geng, G.; Pan, T.; Luo, H.; et al. A SnoRNA-derived piRNA interacts with human interleukin-4 pre-mRNA and induces its decay in nuclear exosomes. Nucleic Acids Res. 2015, 43, 10474-10491. [CrossRef]

246. Li, C.; Zhou, X.; Chen, J.; Lu, Y.; Sun, Q.; Tao, D.; Hu, W.; Zheng, X.; Bian, S.; Liu, Y.; et al. PIWIL1 destabilizes microtubule by suppressing phosphorylation at Ser16 and RLIM-mediated degradation of Stathmin1. Oncotarget 2015, 6, 27794-27804. [CrossRef]

247. Mani, S.R.; Megosh, H.; Lin, H. PIWI proteins are essential for early Drosophila embryogenesis. Dev. Biol. 2014, 385, 340-349. [CrossRef]

248. Tan, H.; Liao, H.; Zhao, L.; Lu, Y.; Jiang, S.; Tao, D.; Liu, Y.; Ma, Y. HILI destabilizes microtubules by suppressing phosphorylation and Gigaxonin-mediated degradation of TBCB. Sci. Rep. 2017, 7, 46376. [CrossRef]

249. Du, W.W.; Yang, W.; Xuan, J.; Gupta, S.; Krylov, S.N.; Ma, X.; Yang, Q.; Yang, B.B. Reciprocal regulation of miRNAs and piRNAs in embryonic development. Cell Death Differ. 2016, 23, 1458-1470. [CrossRef]

250. He, X.; Chen, X.; Zhang, X.; Duan, X.; Pan, T.; Hu, Q.; Zhang, Y.; Zhong, F.; Liu, J.; Zhang, H.; et al. An Lnc RNA (GAS5)/SnoRNA-derived piRNA induces activation of TRAIL gene by site-specifically recruiting MLL/COMPASS-like complexes. Nucleic Acids Res. 2015, 43, 3712-3725. [CrossRef]

(C) 2018 by the authors. Licensee MDPI, Basel, Switzerland. This article is an open access article distributed under the terms and conditions of the Creative Commons Attribution (CC BY) license (http://creativecommons.org/licenses/by/4.0/). 